\title{
Effect of diabetes status and hyperglycemia on global DNA methylation and hydroxymethylation
}

\author{
Jairo Arturo Pinzón-Cortés ${ }^{1,2}$, Angelina Perna-Chaux', Nicolás Steven Rojas-Villamizar1, \\ Angélica Díaz-Basabe', Diana Carolina Polanía-Villanueva1, María Fernanda Jácome1, \\ Carlos Olimpo Mendivil2,3, Helena Groot ${ }^{1,2}$ and Valeriano López-Segura ${ }^{1,2}$ \\ ${ }^{1}$ Biological Sciences Department, Laboratory of Human Genetics, Universidad de los Andes, Bogotá, Colombia \\ ${ }^{2} \mathrm{~S}$ chool of Medicine, Universidad de los Andes, Bogotá, Colombia \\ ${ }^{3}$ Endocrinology Section, Hospital Universitario Fundación Santa Fe de Bogotá, Bogotá, Colombia
}

Correspondence should be addressed to $\mathrm{V}$ López Segura

Email

v.lopez22@uniandes.edu.co

\begin{abstract}
Type 2 diabetes mellitus (T2DM) is characterized by oxidative stress that could lead to chronic micro- and macrovascular complications. We hypothesized that some of the target organ damage is mediated by oxidative alterations in epigenetic mechanisms involving DNA methylation $(5 \mathrm{mC})$ and DNA hydroxymethylation $(5 \mathrm{hmC})$. We analyzed global DNA methylation and hydroxymethylation in peripheral blood cells in wellcontrolled and poorly controlled patients with T2DM and compared them with healthy controls. We also analyzed microarrays of DNA methylation and gene expression of other important tissues in the context of diabetes from the GEO database repository and then compared these results with our experimental gene expression data. DNA methylation and, more importantly, DNA hydroxymethylation levels were increased in poorly controlled patients compared to well-controlled and healthy individuals. Both $5 \mathrm{mC}$ and $5 \mathrm{hmC}$ measurements were correlated with the percentage of glycated hemoglobin, indicating a direct impact of hyperglycemia on changes over the epigenome. The analysis of methylation microarrays was concordant, and $5 \mathrm{mC}$ levels were increased in the peripheral blood of T2DM patients. However, the DNA methylation levels were the opposite of those in other tissues, such as the pancreas, adipose tissue and skeletal muscle. We hypothesize that a process of DNA oxidation associated with hyperglycemia may explain the DNA demethylation in which the activity of ten-eleven translocation (TET) proteins is not sufficient to complete the process. High levels of glucose lead to cellular oxidation, which triggers the process of DNA demethylation aided by TET enzymes, resulting in epigenetic dysregulation of the damaged tissues.
\end{abstract}

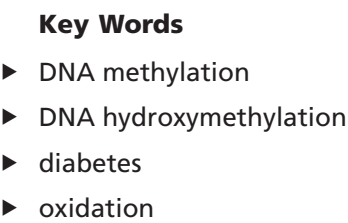

Endocrine Connections (2017) 6, 708-725

\section{Introduction}

Type 2 diabetes mellitus (T2DM) is a complex disease characterized by hyperglycemia secondary to inappropriate insulin secretion, resistance to its action, or both. Over time, these alterations and oxidative stress promote the development of chronic complications with a high burden of morbidity and mortality (1). The chronic complications of T2DM are numerous and include atherosclerotic diseases (coronary artery disease,
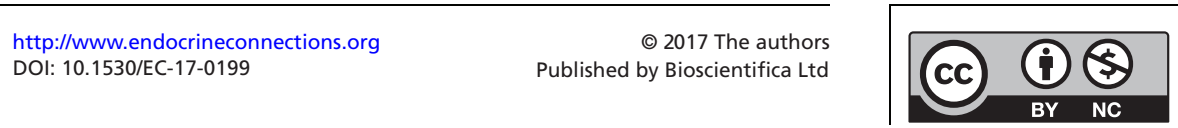

This work is licensed under a Creative Commons Attribution-NonCommercial 4.0 International License. 
atherosclerotic cerebrovascular disease and peripheral arterial disease) and microvascular diseases (neuropathy, retinopathy and neuropathy), plus many other alterations that predispose to cognitive decline and bone fragility. Diabetes is a worldwide public health issue. By 2013, the number of patients with diabetes was estimated at 381 million. Projections from the International Diabetes Federation predict that by the year 2030, most growth in new diabetes cases will come from developing countries, where a prevalence increase of $69 \%$ is expected (2).

The parallel among rapid urbanization, change in lifestyle habits and rapid surge in diabetes prevalence across the world during the second half of the 20th century suggests that environmental factors are the predominant force driving the occurrence of diabetes at the population level. This environmental influence can also be explained from an epigenetic perspective. For example, the fetus and neonate development conditions have a significant influence on the onset of T2DM and obesity without inducing genetic changes in the DNA sequence $(3,4,5,6)$. On the other hand, epigenetic factors may play a role in the development of T2DM itself and in the susceptibility to developing chronic complications through alterations of genetic expression in the vasculature of most affected tissues $(7,8,9,10)$. Another manifestation of epigenetic changes in patients with diabetes is the so-called metabolic memory, whereby patients who have been poorly controlled during some time in the disease course seem to carry epigenetic changes that persist for many years and predispose them to developing complications $(9,11,12,13)$

Several studies in patients with T2DM have found changes in the genome methylation profile, such as a reduced level of DNA methylation, which may induce changes in the gene expression that favor the development of many features of the diabetes phenotype and of endorgan complications $(14,15)$. In a rat model of type 1 diabetes mellitus (T1DM), Williams and coworkers (16) found alterations of the one-carbon cycle, accompanied by DNA hypomethylation in the liver and not in the kidney tissue. Another study in the Zucker diabetic fatty rat model of T2DM found DNA hypermethylation of pancreatic tissue. These results show that methylation and demethylation processes in diabetes may be differently affected depending on the local conditions and tissue exposed to the disease (17). Concerning the source of the observed differences in DNA methylation, they can be attributed to different factors, but an essential role is played by methyltransferase enzymes, especially DNA methyl transferase-1 (DNMT1), which is responsible for the maintenance of DNA methylation after cell divisions. Also, disturbances of the S-adenosylmethionine (SAM) to S-adenosylhomocysteine ratio may contribute to global changes in methylation, affecting the level of available SAM to perform DNA methylation. Additionally, suppressed mitochondrial activity in diabetes may in turn reduce the production and availability of SAM $(1,17,18,19,20,21$, $22)$. Furthermore, a prominent role of ncRNAs has been identified in the vascular system in response to oxidative stress in diabetes (10). The function of these miRNAs can also be derived from their role on methylation, such as miRNA133, which modulates the synthesis of DNMT. A low expression of miRNA133a might be related to an increase in overall DNA methylation (23).

A lesser-known phenomenon of epigenetic regulation is DNA demethylation, which logically has an important role in the deletion of information during the development of a new body or simply on changes in the gene expression throughout the cell cycle. The oxidation of 5-methylcytosines ( $5 \mathrm{mC})$ to 5-hydroxymethylcytosines (5hmC), followed by a DNA repair process, has been proposed as an active mechanism that can explain the process of demethylation. This oxidation can be mediated by enzymes of the ten-eleven translocation (TET) family $(24,25,26)$. The role of TET enzymes in DNA demethylation has been actively studied, and recently, a crucial role has been observed for their expression in stem cells and during processes of differentiation and cell reprogramming $(24,25,26,27)$. In addition to active demethylation catalyzed by enzymes, the methyl group of cytosine can be eliminated by passive processes, such as lack of function of DNMT1, allowing for the loss of methylation through cell divisions $(28,29)$.

Given the power of epigenetics to explain metabolic memory and other pivotal phenomena in patients with diabetes, we aimed to study whether the peripheral blood cells of patients with T2DM show dysregulation of DNA methylation and hydroxymethylation, which is probably mediated by a pro-oxidant state. To this end, we quantitated the global levels of $5 \mathrm{mC}$ and $5 \mathrm{hmC}$ in the peripheral blood of patients with T2DM with good or poor glycemic control and then compared them to those of healthy controls. In addition, we analyzed the expression of three of the most important enzymes in the demethylation process, namely DNMT1, ten-eleven translocation 1 (TET1) and activation-induced cytidine deaminase (AID), with other possibly altered genes in the disease development. Furthermore, we studied global methylation and hydroxymethylation and the expression of the demethylation machinery in previously published

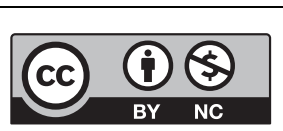

This work is licensed under a Creative Commons Attribution-NonCommercial 4.0 International License. 


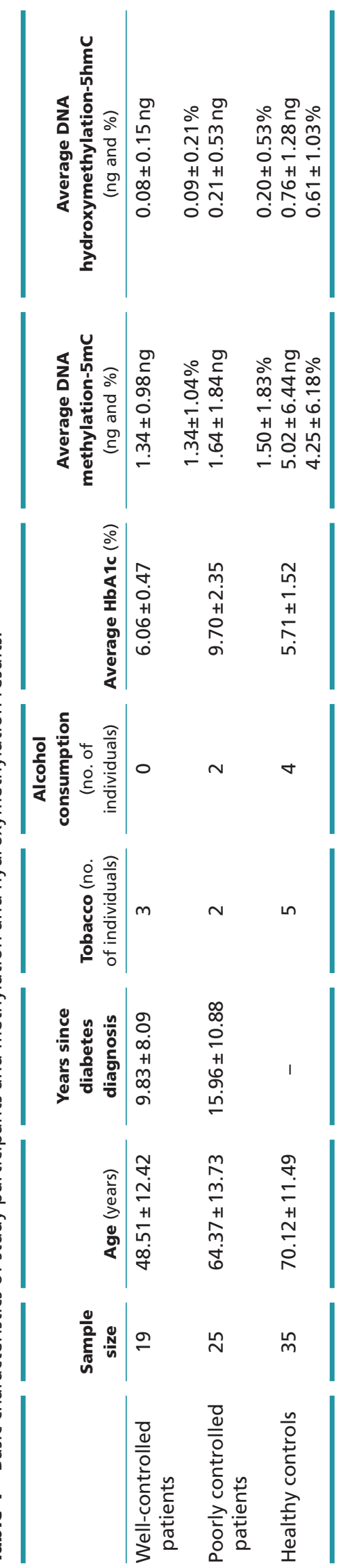

http://www.endocrineconnections.org DOI: 10.1530/EC-17-0199 microarray data from several tissues to find an explanation for the methylome alterations in our patients.

\section{Materials and methods}

\section{Patients and samples}

Peripheral blood $(5 \mathrm{~mL})$ was collected from each of the 44 patients with T2DM and 35 healthy controls who freely agreed to participate in the study. The research was approved by the ethics committees of both participating institutions of Universidad de los Andes and Fundación Santa Fe de Bogotá. Written informed consent was obtained from the participants. Relevant sociodemographic and clinical information, including the age, time since T2DM diagnosis, current medications, tobacco and alcohol consumption, was also collected (Table 1).

\section{$5 \mathrm{mC}$ and $5 \mathrm{hmC}$ quantitation}

Genomic DNA was extracted using a commercial kit (GeneJET whole blood genomic DNA purification mini kit - Thermo Scientific). The quality and integrity of DNA were assessed by spectrophotometry on a NanoDrop spectrophotometer (Thermo Scientific). Only samples with OD 260/280 ratios between 1.8 and 2.1 were used.

Global DNA methylation and hydroxymethylation weremeasuredusingcommercialkitsfrom Abcam:EpiSeeker methylated DNA Quantification Kit (Fluorometric) (ab117129) and EpiSeeker Hydroxymethylated DNA Quantification Kit (Fluorometric) (ab117131). Fluorescence was read with a Synergy HT Multi-Mode Microplate Reader (BioTek) at a wavelength of 530/590 excitation/emission.

We used the commercial negative control subtracting value of relative fluorescence units for all measurements to correct for background fluorescence. For quantitation, we built a calibration curve for each experiment $(0.5,1.0$, 2.0, 5.0 and $10.0 \mathrm{ng} / \mathrm{\mu L}$ for $5 \mathrm{mC}$ and $0.2,0.5,1.0,2.0$ and $5.0 \mathrm{ng} / \mathrm{\mu L}$ for $5 \mathrm{hmC}$ ). With these curves, we calculated the levels of $5 \mathrm{mC}$ and $5 \mathrm{hmC}$ in each sample as well as calculated the percentages of $5 \mathrm{mC}$ and $5 \mathrm{hmC}$ in each sample. The calibration curve and negative controls were measured in duplicate and the samples in triplicate.

\section{Gene expression and quantitative PCR}

Total RNA was extracted from peripheral blood samples with TRIzol reagent (Invitrogen) according to the

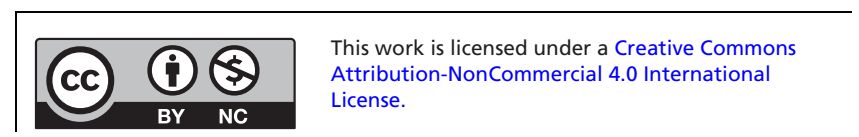


Table 2 Primers used for qRT-PCR and Bisulfite transformed DNA MS-qPCR.

\begin{tabular}{l} 
Primer \\
\hline DNMT1 \\
TET1 \\
AID \\
OGG1 \\
External IL-6 \\
IL-6 methylated \\
IL-6 unmethylated \\
External TNF- $\alpha$ \\
TNF- $\alpha$ methylated \\
TNF- $\alpha$ unmethylated
\end{tabular}

\begin{tabular}{l} 
Forward primer \\
\hline GCACGAATTTCTGCAAACAG \\
TTCTGACAAGAGCTGGAGCA \\
TTATCTTCGCAATAAGAACGGCT \\
ACTGTCACTAGTCTCACCAG \\
GGTTTTTGAATTAGTTTGATT \\
GAAATTTTTGGGTGTCGACGC \\
GAAATTTTTGGGTGTTGATGT \\
GGGTTTTATATATAAATTAGTTAG \\
TTGAGACGTTTCGTTGGGCGC \\
TTGAGATGTTTTGTTGGGTGT
\end{tabular}

manufacturer's instructions. The quality and integrity of RNA were analyzed by spectrophotometry on a NanoDrop (Thermo Scientific). Only samples with values of the OD260/OD280 ratio between 1.8 and 2.1 were used for reverse transcription. RNA integrity was checked by electrophoresis in a $1 \%$ agarose gel under denaturing conditions. The two subunits of ribosomal RNA (18S and 28S) were visualized for each sample.

cDNA was synthesized using an IMPROM II reverse transcriptase kit (Promega) according to the manufacturer's specifications. Then, $1 \mu \mathrm{g}$ of RNA was used for cDNA synthesis. The cDNA was quantified by spectrophotometry on a NanoDrop (Thermo Scientific). This kit allows for the preferential enrichment of mRNA using poly-T oligonucleotides in the cDNA transcription and discarding other types of RNA present in the extracted samples. cDNA synthesis quality was confirmed with conventional PCR amplification of an internal control of gene expression, GAPDH. This was confirmed through agarose gel electrophoresis of samples, amplifying GAPDH by PCR using CDNA as input. When this step was successful, samples were used in a qRT-PCR experiment with Applied Biosystems Power SYBR Green Master Mix to quantify the differential gene expression of several genes of interest. A standard curve was used to obtain efficiency

\begin{tabular}{lcc} 
Reverse primer & & $\begin{array}{c}\text { Size of } \\
\text { amplicon }(\mathrm{bp})\end{array}$ \\
${$\cline { 1 - 2 }$} }$ & 176 \\
TGGAACCTTTTTGGATTTGG & 170 \\
TCGGGCACAGTCGTAGCAGGG & 136 \\
CCTTCCGGCCCTTTGGAAC & 156 \\
CCCTATAAATCTTGATTTAAAAT & 132 \\
AAAACTACGAACGCAAACACG & 67 \\
AAAACTACAAACACAAACACA & 67 \\
TAATAAACCCTACACCTTCTA & 187 \\
AAAAAAACCGCGACGACGACC & 149 \\
AAAAAAACCACAACAACAACC & 149 \\
\hline
\end{tabular}

with dilutions of a cDNA pool of known concentration. Unknown samples were measured in triplicate, and standards were measured in duplicate. The average CT was used to compare gene expressions. The primers and thermal profile used are available with their respective TM for the amplified genes (DNMT1, TET1, AID and OGG1; Tables 2 and 3). We used REST gene quantification software to estimate the relative expression and relative methylation of quantitative methylation-specific PCR (qMS-PCR).

\section{Promoter methylation status}

Bisulfite conversion of DNA was performed according to the supplier EZ DNA Methylation-Gold Kit. We used $200 \mathrm{ng}$ of DNA for each sample in the reaction, and $1 \mu \mathrm{L}$ of each bisulfite-treated DNA sample was used in the qMS-PCR to quantify the degree of methylation of the promoters for two genes that are putatively involved in diabetes pathophysiology, namely IL- 6 and TNF- $\alpha$. We used a nested PCR as previously reported for both genes. The thermal profiles for all PCR protocols are available in Table 3. We used a subtractive method (30) and REST gene quantification software to determine the relative levels of promoter methylation.

Table 3 PCR thermal profiles used for each of the targets amplified.

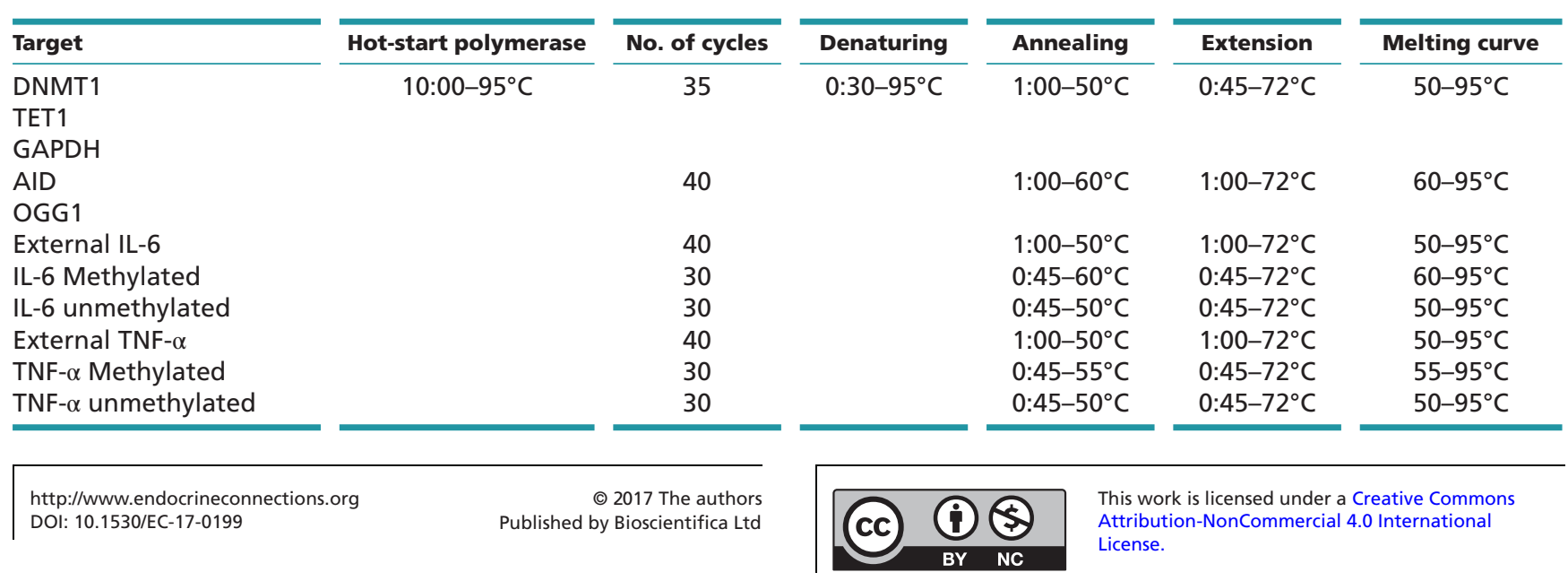




\section{Measurement of glycated hemoglobin}

Glycated hemoglobin A1c (HbA1c) was measured with a commercial kit NycoCard HbA1c with a NycoCard READER II device in accordance with the manufacturer's instructions. Based on this result, the samples were divided into the following three groups: (1) patients with poorly controlled T2DM (HbA1c $\geq 7 \%)$, (2) patients with well-controlled T2DM (HbA1c $<7 \%$ ) and (3) samples from healthy controls without diagnosed diabetes or any other relevant comorbidity. The controls also had an $\mathrm{HbA1c}$ level in the non-diabetic range (below 5.71\%).

\section{Genome-wide gene-specific DNA methylation and expression by microarrays}

A total of 416 microarrays were analyzed from the NCBI dataset Gene Expression Omnibus (GEO) (31): 317 Illumina Human Methylation 27 BeadChips (HumanMethylation27_270596_v.1.2) obtained from the experiments; GSE21232 (pancreatic islets), GSE34008 (whole blood), GSE38291 (muscle and adipose tissue), GSE20067 (whole blood), GSE57285 (healthy control), GSE61611 (healthy control), 18 Illumina Human Ref-8 v3.0 expression BeadChips and 18 Exiqon miRCURY LNA microRNA Array, v.11.0 chips, obtained from the experiment GSE26168 (whole blood) and 63 Affymetrix Human Gene 1.0 ST Array chips obtained from experiments GSE38642 (pancreatic islets).

\section{Statistical methods}

The normality assumption of continuous variables was conducted with the Shapiro-Wilk test. The equality of variance assumption was conducted using an $F$-test. For variables that did not deviate from a normal distribution, Student's $T$ test or Welch $T$ test was employed. For variables that deviated from a normal distribution, 2-group comparisons were made with Wilcoxon's test. Mean comparisons across more than 2 groups were executed with the Kruskal-Wallis test or oneway ANOVA. Both Spearman and Kendall correlations were employed when two continuous variables were compared.

To know the influence of the other studied variables of the samples, a multivariate study was performed based on $n p m v$ package on $\mathrm{R}$ software. This package uses 4 different non-parametric tests of inference estimation:
ANOVA-type test, McKeon approximation for the Lawley Hotelling Test, Muller approx. for the Bartlett-NandaPillai Test and Wilks Lambda Test (32). Based on the results obtained, a model analysis based on the Akaike information criterion (AIC) was developed in order to discover which variables could be the main cause of the levels of methylation and hydroxymethylation (33).

Hierarchical clustering analysis of microarrays was performed using standard correlation coefficients; for the cluster method, similarity metric and centroid linkage were used. Briefly, the mean fluorescence intensity value obtained for each tested spot was introduced into a dedicated database system (Microsoft Excel). Clustering was performed after median-centering and normalizing the fluorescence ratios. A logarithmic (base 2) transformation was applied to the values of this ratio for individual datasets. The resultant normalized $\log 2$ ratios were used for further statistical analysis with the Cluster 3.0 (C Clustering Library 1.5) and Java Treeview 1.1.6r2 programs. All statistical analyses were performed and graphs generated in statistical software R version 3.2.3. (http://www.r-project.org).

\section{Ethics approval and consent to participate}

The authors of this paper declare that both protocol and informed consent were approved by the University ethics committees (Comité de ética de la Universidad de los Andes) and by the Ethics Committee of the hospital that provided the samples (Comité de ética en investigación del Hospital Universitario Fundación Santa Fe de Bogotá). Likewise, patients who participated in the study were appropriately briefed and signed informed consent.

\section{Consent for publication}

All researchers give their permission for the publication of this study.

\section{Availability of data and materials}

A minimal dataset is publicly available using the access number in the 'Materials and methods' section. The following are the access numbers for the NCBI GEO database: GSE21232, GSE34008, GSE38291, GSE20067, GSE57285, GSE61611, GSE26168, GSE38642. http://www.endocrineconnections.org
DOI: 10.1530/EC-17-0199 (c) 2017 The authors Published by Bioscientifica Ltd
This work is licensed under a Creative Commons Attribution-NonCommercial 4.0 International License. 


\section{Results}

\section{Effect of diabetic status and hyperglycemia on DNA methylation and hydroxymethylation in T2DM}

Global DNA methylation in whole blood cells was not significantly different between patients with T2DM and controls (Fig. 1A; Supplementary Fig. 1, see section on supplementary data given at the end of this article). However, when patients were classified according to metabolic control (HbA1c $\geq 7 \%$ vs $\mathrm{HbA} 1 \mathrm{c}<7 \%$ ), it became apparent that while well-controlled patients had methylation levels similar to controls, poorly controlled patients exhibited markedly higher global DNA methylation ( $P$-value for uncontrolled patients vs healthy controls $=0.011$ and $P$-value for comparison between the two groups of patients=0.0039) (Fig. 1C). The influence of metabolic control is such that when the healthy control and the well-controlled groups were combined and compared to the poorly controlled patients, the difference in DNA methylation remained clearly significant $(P<0.001)$ (Fig. $1 \mathrm{E})$.

Interestingly, despite the strong difference, when analyzing the methylation levels vs glycemic control in poorly controlled patients, a strong negative correlation
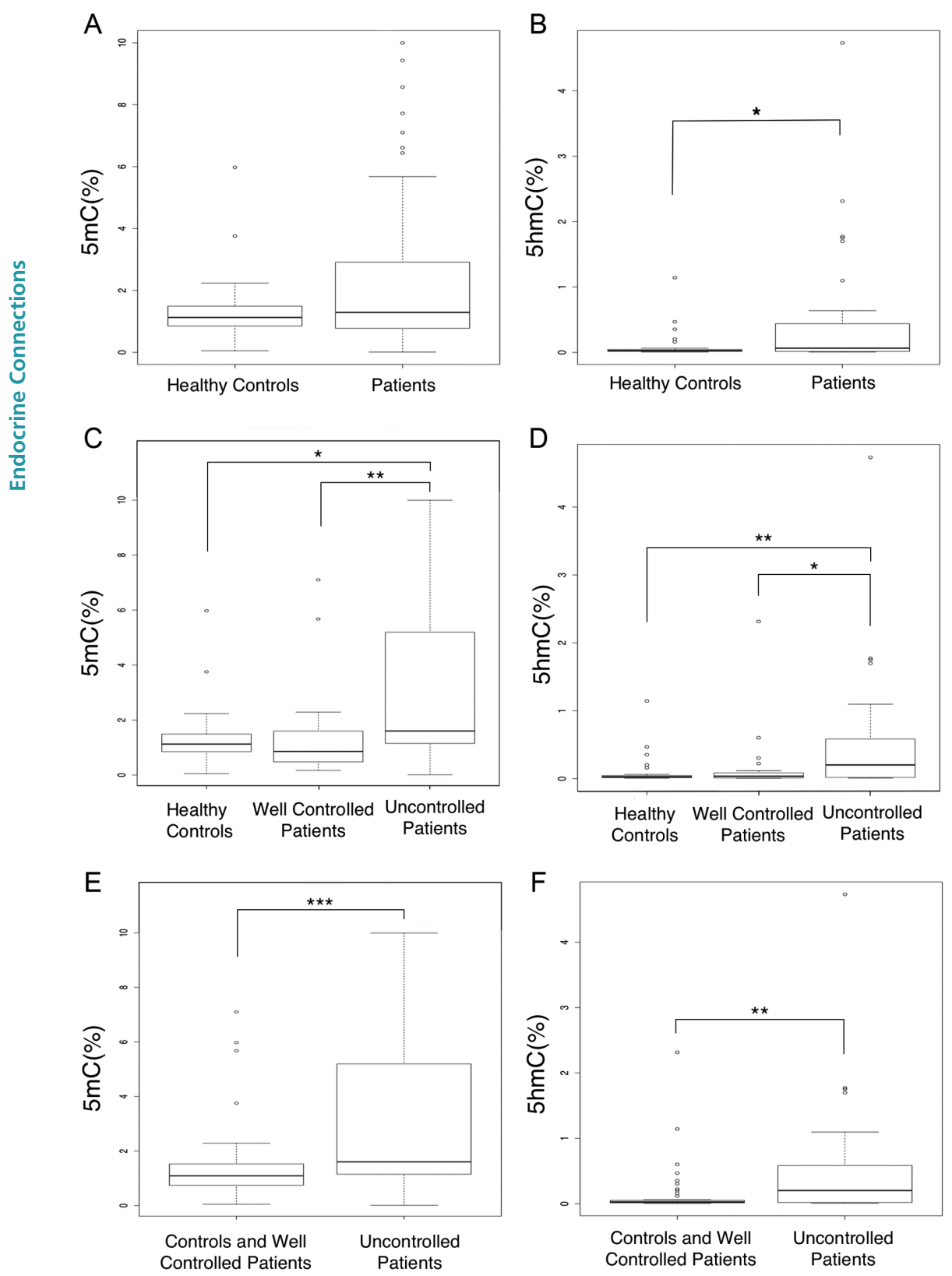

Figure 1

Percentage of global DNA methylation and hydroxymethylation. (A) Global DNA methylation in healthy controls vs patients. (B) Global DNA hydroxymethylation in healthy controls vs patients. (C) Global DNA methylation in healthy controls, controlled patients and poorly controlled patients. (D) Global DNA hydroxymethylation in healthy controls, controlled patients and poorly controlled patients. (E) Global DNA methylation in healthy controls and controlled patients vs poorly controlled patients. (F) Global DNA hydroxymethylation in healthy controls and controlled patients vs poorly controlled patients. The comparison was conducted using the Wilcoxon rank sum test. ${ }^{*} P<0.05,{ }^{*} P<0.01$, and $* * * P<0.001$. The method used for $5 \mathrm{mC}$ and $5 \mathrm{hmC}$ estimation was ELISA ab117129 and ab117131, respectively. http://www.endocrineconnections.org DOI: 10.1530/EC-17-0199 (c) 2017 The authors Published by Bioscientifica Ltd
This work is licensed under a Creative Commons Attribution-NonCommercial 4.0 International License. 
was observed $(\mathrm{Tau}=-0.3838, P$-value $=0.0076)$, which would be much more in agreement with the data we have from other tissues (Supplementary Fig. 1G).

The results for hydroxymethylation were even more interesting because we found significant differences between patients and controls $(P=0.045$, Fig. 1B; Supplementary Fig. 1), and controlled patients showed levels below those of uncontrolled patients with a significant difference $(P=0.015)$. As expected, the difference between controls and poorly controlled patients was also significant $(P=0.002)$ (Fig. 1D). As in the case of methylation, when healthy controls and well-controlled patients are treated as a group, they differed from poorly controlled patients $(P=0.0034)$ (Fig. 1F).

\section{Sex and lifestyle factors}

The levels of $5 \mathrm{mC}$ and $5 \mathrm{hmC}$ did not differ between the sexes (Fig. 2A and B). There was also no difference between alcohol consumers and non-consumers (Fig. 2C and D) or between smokers and non-smokers (Fig. 2E and F).

Given that it is already known that alcohol and tobacco induce epigenetic alterations at different levels, we performed an exploratory sensitivity analysis that excluded alcohol and tobacco consumers. The results of this analysis were virtually indistinguishable from those with the complete dataset, except that several previously significant comparisons became non-significant, which was probably due to the smaller sample size (Fig. 3).

\section{Age and disease duration}

Aging is known to correlate with changes in the methylome, and we expected patients with T2DM to be no exception (34). However, we did not find a linear correlation between DNA methylation and age. Regarding hydroxymethylation, there was a significant but mild correlation with age. By contrast, there was no linear correlation between diabetes duration and levels of DNA methylation or hydroxymethylation (Fig. 4).

\section{Multivariate analysis of $5 \mathrm{mC}$ and $5 \mathrm{hmC}$ levels}

To evaluate the effect of possible confounding variables over the levels of DNA methylation and hydroxymethylation, we performed a multivariate analysis with different sets of known epigenetic modifiers included in the study. First, and according to the nonparametric distribution of the variables assessed, we used the $n p m v$ package on $\mathrm{R}$ software to estimate the inference of our multivariate data (32). We obtained, using multiple test statistics, results that reject the hypothesis of equality among the explanatory variables included in the multivariate analysis and the factors inside the response variable (groups of treatment).
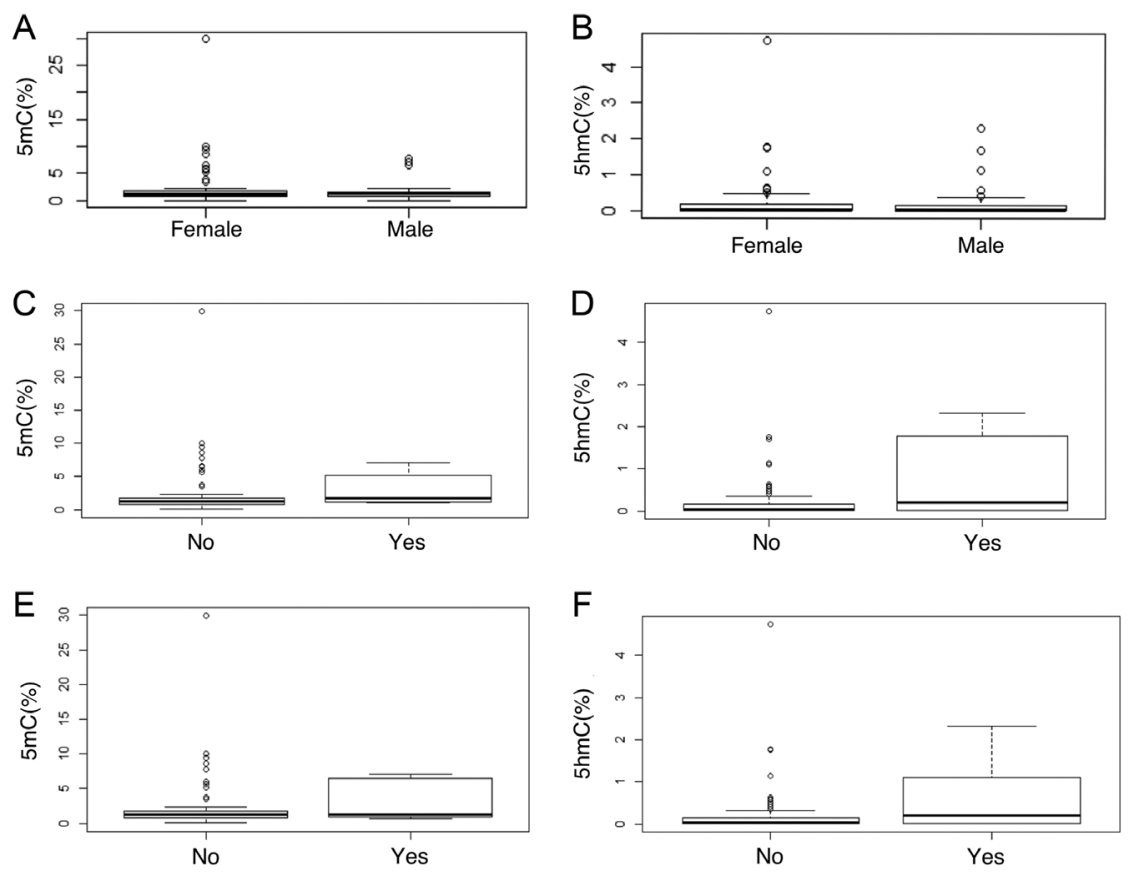

Figure 2

Differences in global methylation and hydroxymethylation by sex (A and $B$ ), alcohol consumption ( $C$ and $\mathrm{D}$ ) and tobacco use ( $\mathrm{E}$ and $\mathrm{F}$ ). The comparison was conducted using the Wilcoxon rank sum test. ${ }^{*} P<0.05, * * P<0.01$, and $* * * P<0.001$. The method used for $5 \mathrm{mC}$ and $5 \mathrm{hmC}$ estimation was ELISA ab117129 and ab117131, respectively. http://www.endocrineconnections.org DOI: 10.1530/EC-17-0199
() 2017 The authors Published by Bioscientifica Ltd
This work is licensed under a Creative Commons Attribution-NonCommercial 4.0 International License. 

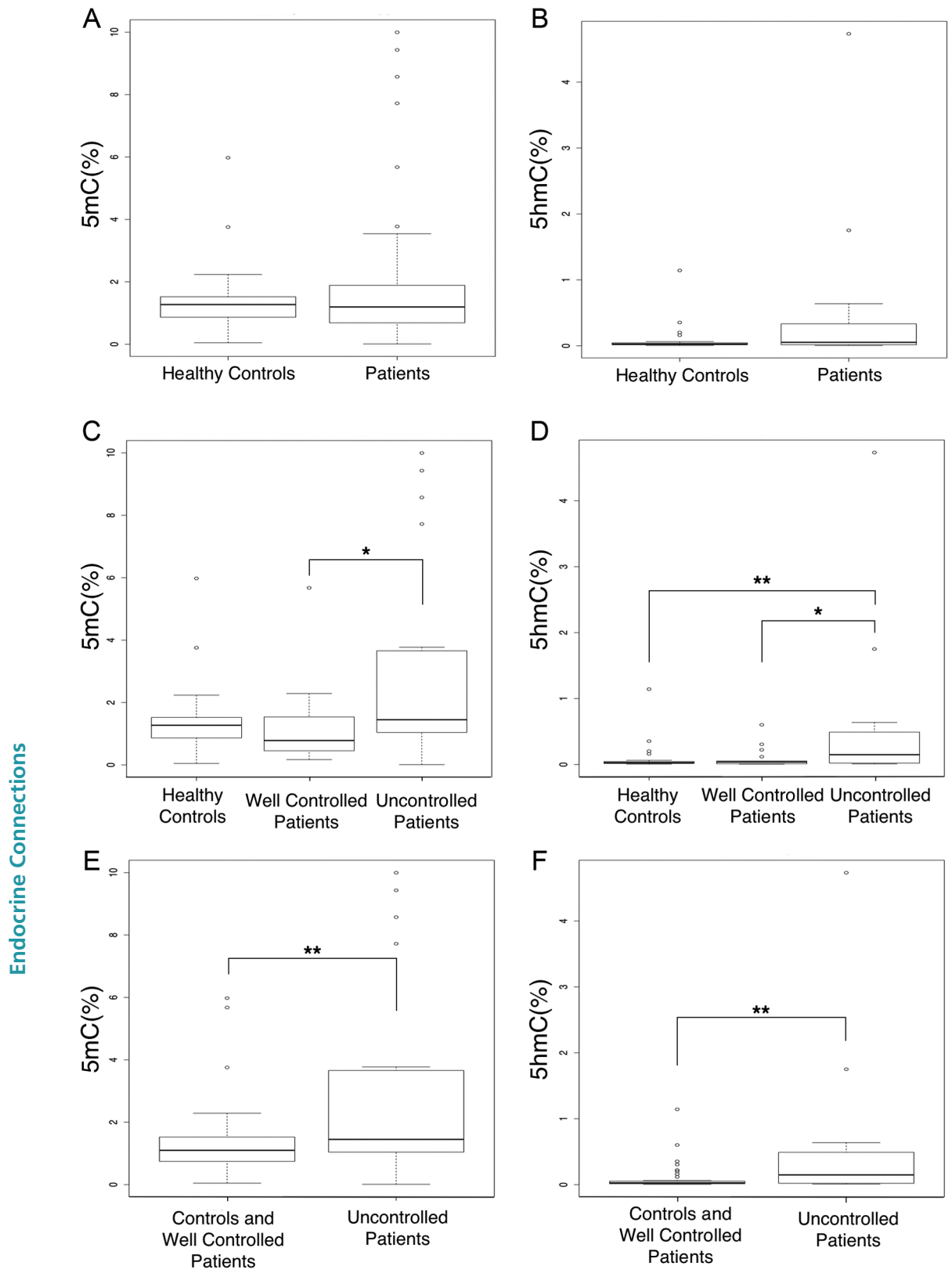

Figure 3

Percentages of methylation ( $\mathrm{A}, \mathrm{C}$ and $\mathrm{E})$ and hydroxymethylation (B, D and F), excluding data from alcohol and tobacco consumers. The comparison was conducted using the Wilcoxon rank sum test. ${ }^{*} P<0.05,{ }^{*} * P<0.01$, and $* * * P<0.001$. The method used for $5 \mathrm{mC}$ and $5 \mathrm{hmC}$ estimation was ELISA ab117129 and ab117131, respectively.

To ascertain some of the factors influencing the epigenetic pattern of the cytosine modifications studied, and if our hypothesis related to the level of glucose control affected these patterns, we take the $5 \mathrm{mC}$ and $5 \mathrm{hmC}$ levels as response variables and included other variables both continuous and categorical as possible explanatory variables in an AIC modeling system (33). We considered the possible interaction of some of the explanatory variables like age, sex, years since diabetes diagnosis (TimeDx), tobacco and alcohol consumption, and average of $\mathrm{HbA1c}$.

We tested at least 14 models and found that in the case of $5 \mathrm{mC}$ (Table 4 ), the model that better approximates

\begin{tabular}{lr}
\hline http://www.endocrineconnections.org & ○ 2017 The authors \\
DOI: $10.1530 /$ EC-17-0199 & Published by Bioscientifica Ltd
\end{tabular}

the values obtained was the one that included $\mathrm{HbA1c}$, the age, the time since diagnosis (TimeDx), sex and the interaction term between HbA1c and age (model 10). It was followed closely by model 5 that did not included sex, and model 6 with an additional interaction term between HbA1c and time since diagnosis. These results are consistent with the expectations, because all sex, age, HbA1c and the time since diabetes diagnosis affect DNA methylation.

In the same way, for the explanatory models of the levels of $5 \mathrm{hmC}$, after the same AIC analysis, the most weighted models were 4, 7 and 14 (Table 5). The model 4 included $\mathrm{HbA1c}$, age and the time since diagnosis.

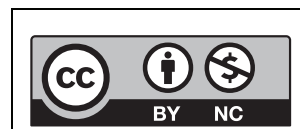

This work is licensed under a Creative Commons Attribution-NonCommercial 4.0 International License. 
A
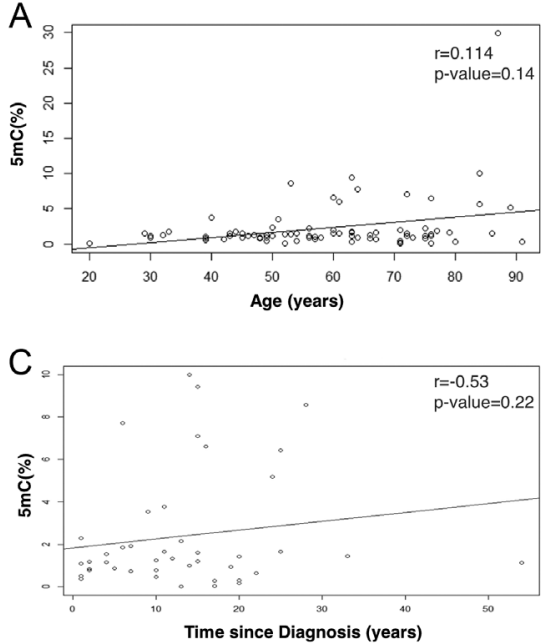

B
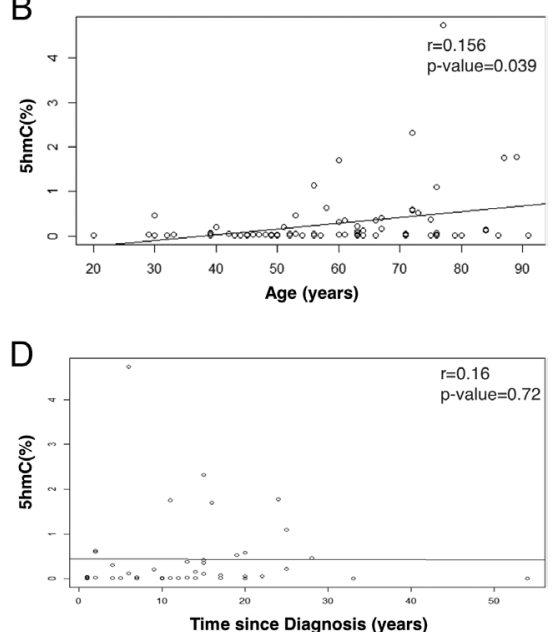

Figure 4

Correlation between age ( $A$ and $B$ ) and years since diagnosis of diabetes ( $C$ and $D$ ) with the percentages of $5 \mathrm{mC}$ and $5 \mathrm{hmC}$. The correlation was conducted using Spearman's rank. The method used for $5 \mathrm{mC}$ and $5 \mathrm{hmC}$ estimation was ELISA ab117129 and ab117131, respectively.
Model 7 also included sex and model 14 the interaction term between time since diagnosis and HbA1c. This also has biological plausibility considering these factors as possible influencers of the oxidative cellular levels, and the $5 \mathrm{hmC}$ as a byproduct of this and other mechanisms. In both $5 \mathrm{mC}$ and $5 \mathrm{hmC}, \mathrm{HbA} 1 \mathrm{c}$ was definitely included as a main explanatory variable, thus confirming our hypothesis of the correspondence between diabetes and glucose control, and a metabolic mark over the epigenome.

\section{Genome-wide gene-specific DNA methylation in other tissues in diabetes}

Several publications over the last decade have reported an association between diabetes and DNA demethylation (11), but this was not the case in our study. Also, not only were the methylation levels tissue-specific, but their relationship to other variables was also tissue-specific. For instance, aging is associated with progressive hypomethylation in the heart, liver or intestine, while it is associated with increased methylation in the kidneys (35). For this reason, we tried to confirm the findings from our patients with those genome-wide gene-specific DNA methylation in microarray samples from the peripheral blood of patients with T2DM, T2DM with diabetic nephropathy and healthy controls (Fig. 5).

The result of the clustering algorithm reflected a clear grouping of controls vs T2DM patients, confirming the results obtained from our patients (Fig. 5A and Supplementary Fig. 2). While some groups of genes showed higher methylation in the peripheral blood of controls, methylation was increased in diabetes for a large majority of the genes. This epigenomic distribution in genome-wide gene-specific DNA methylation was clearly different between controls and diabetic patients with an increased methylation in diabetes $(P<0.001)$ (Fig. 5B).

Table 4 Multivariate explanatory models of $5 \mathrm{mC}$ levels performanced by AIC.

\section{Model}

1. $5 \mathrm{mC}=\mathrm{HbA} 1 \mathrm{c}$

2. $5 \mathrm{mC}=\mathrm{HbA} 1 \mathrm{c}+\mathrm{Age}$

3. $5 m \mathrm{mC}=\mathrm{HbA} 1 \mathrm{c}+\mathrm{Age}+\mathrm{Age} * \mathrm{HbA} 1 \mathrm{c}$

4. $5 \mathrm{mC}=\mathrm{HbA} 1 \mathrm{c}+\mathrm{Age}+\mathrm{TimeDx}+\varepsilon$

5. $5 m \mathrm{mC}=\mathrm{HbA} 1 \mathrm{c}+\mathrm{Age}+\mathrm{TimeDx}+\mathrm{Age} * \mathrm{HbA} 1 \mathrm{c}+\varepsilon$

6. $5 \mathrm{mC}=\mathrm{HbA} 1 \mathrm{c}+\mathrm{Age}+\mathrm{TimeDx}+\mathrm{Age} * \mathrm{HbA} 1 \mathrm{c}+\mathrm{TimeD} * \mathrm{HbA} 1 \mathrm{c}+\varepsilon$

7. $5 \mathrm{mC}=\mathrm{HbA} 1 \mathrm{c}+\mathrm{Age}+\mathrm{TimeDx}+\mathrm{Sex}+\varepsilon$

8. $5 \mathrm{mC}=\mathrm{HbA} 1 \mathrm{c}+\mathrm{Age}+\mathrm{TimeDx}+\mathrm{Sex}+\mathrm{Alcohol}+\varepsilon$

9. $5 \mathrm{mC}=\mathrm{HbA} 1 \mathrm{c}+\mathrm{Age}+\mathrm{TimeDx}+\mathrm{Sex}+$ Alcohol + Smoking $+\varepsilon$

10. $5 \mathrm{mC}=\mathrm{HbA} 1 \mathrm{c}+\mathrm{Age}+\mathrm{TimeDx}+\mathrm{Sex}+\mathrm{Age} * \mathrm{HbA} 1 \mathrm{c}+\varepsilon$

11. $5 \mathrm{mC}=\mathrm{Age}+\varepsilon$

12. $5 \mathrm{mC}=(\mathrm{HbA} 1 \mathrm{c})^{\wedge} 2+\varepsilon$

13. $5 \mathrm{mC}=(\mathrm{HbA} 1 \mathrm{c})^{\wedge} 3+\varepsilon$

14. $5 m C=H b A 1 c+A g e+T i m e D x+T i m e D x * H b A 1 c+\varepsilon$

\begin{tabular}{c} 
AICC \\
\hline 370.3415 \\
352.9921 \\
352.2571 \\
216.9408 \\
215.9245 \\
216.6916 \\
217.6731 \\
219.9179 \\
219.6062 \\
215.8809 \\
350.8423 \\
370.3415 \\
354.5804 \\
218.8692
\end{tabular}

\begin{tabular}{c}
\hline$\Delta$ AICc \\
\hline 154.4606 \\
137.1112 \\
136.3762 \\
1.0599 \\
0.0436 \\
0.8107 \\
1.7922 \\
4.037 \\
3.7253 \\
0 \\
134.9614 \\
154.4606 \\
138.6995 \\
2.9883
\end{tabular}

Wi

0.00

0.00

0.00

0.14

0.24

0.16

0.10

0.03

0.04

0.24

0.00

0.00

0.00

0.05

$+\varepsilon$, error; AICC, corrected Akaike information criteria; $\triangle \mathrm{AICC}$, delta corrected Akaike information criteria; Wi, weights of each models.

(c) 2017 The authors
Published by Bioscientifica Ltd

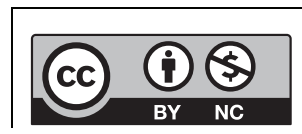

This work is licensed under a Creative Commons Attribution-NonCommercial 4.0 International License. 
Table 5 Different explanatory models of $5 \mathrm{hmC}$ levels performanced by AIC.

\begin{tabular}{|c|c|c|c|}
\hline Model & AICc & $\triangle \mathrm{AICc}$ & Wi \\
\hline 1. $5 \mathrm{hmC}=\mathrm{HbA} 1 \mathrm{c}+\varepsilon$ & 164.7843 & 46.14 & 0.00 \\
\hline 2. $5 \mathrm{hmC}=\mathrm{HbA} 1 \mathrm{c}+\mathrm{Age}+\varepsilon$ & 162.6014 & 43.96 & 0.00 \\
\hline 3. $5 \mathrm{hmC}=\mathrm{HbA} 1 \mathrm{c}+\mathrm{Age}+\mathrm{Age} * \mathrm{HbA} 1 \mathrm{c}+\varepsilon$ & 164.8128 & 46.17 & 0.00 \\
\hline 4. $5 \mathrm{hmC}=\mathrm{HbA} 1 \mathrm{c}+\mathrm{Age}+\mathrm{TimeDx}+\varepsilon$ & 118.6397 & 0 & 0.34 \\
\hline 5. $5 \mathrm{hmC}=\mathrm{HbA} 1 \mathrm{c}+\mathrm{Age}+\mathrm{TimeDx}+\mathrm{Age} * \mathrm{HbA} 1 \mathrm{c}+\varepsilon$ & 121.7168 & 3.08 & 0.07 \\
\hline 6. $5 \mathrm{hmC}=\mathrm{HbA} 1 \mathrm{c}+\mathrm{Age}+\mathrm{TimeDx}+\mathrm{Age} * \mathrm{HbA} 1 \mathrm{c}+$ TimeDx $* \mathrm{HbA} 1 \mathrm{c}+\varepsilon$ & 123.1482 & 4.51 & 0.03 \\
\hline 7. $5 \mathrm{hmC}=\mathrm{HbA} 1 \mathrm{c}+\mathrm{Age}+\mathrm{TimeDx}+\mathrm{Sex}+\varepsilon$ & 119.8585 & 1.22 & 0.18 \\
\hline 8. $5 \mathrm{hmC}=\mathrm{HbA} 1 \mathrm{c}+\mathrm{Age}+\mathrm{TimeDx}+\mathrm{Sex}+$ Alcohol $+\varepsilon$ & 121.0017 & 2.36 & 0.10 \\
\hline 9. $5 \mathrm{hmC}=\mathrm{HbA} 1 \mathrm{c}+\mathrm{Age}+\mathrm{TimeDx}+\mathrm{Sex}+$ Alcohol + Smoking $+\varepsilon$ & 121.6366 & 3 & 0.07 \\
\hline 10. $5 \mathrm{hmC}=\mathrm{HbA} 1 \mathrm{c}+\mathrm{Age}+$ TimeDx $+\mathrm{Sex}+\mathrm{Age} * \mathrm{HbA} 1 \mathrm{c}+\varepsilon$ & 122.0947 & 3.46 & 0.06 \\
\hline 11. $5 \mathrm{hmC}=\mathrm{Age}+\varepsilon$ & 162.6202 & 43.98 & 0.00 \\
\hline 12. $5 \mathrm{hmC}=(\mathrm{HbA} 1 \mathrm{c})^{\wedge} 2+\varepsilon$ & 164.7843 & 46.14 & 0.00 \\
\hline 13. $5 \mathrm{hmC}=(\mathrm{HbA} 1 \mathrm{c})^{\wedge} 3+\varepsilon$ & 164.7843 & 46.14 & 0.00 \\
\hline 14. $5 \mathrm{hmC}=\mathrm{HbA} 1 \mathrm{c}+\mathrm{Age}+$ TimeDx + TimeDx $* \mathrm{HbA} 1 \mathrm{c}+\varepsilon$ & 120.470 & 1.830 & 0.14 \\
\hline
\end{tabular}

$\varepsilon$, error; AICc, corrected Akaike information criteria; $\triangle \mathrm{AICC}$, delta corrected Akaike information criteria; Wi, weights of each models.

A very interesting result is the lack of differentiation between general T2DM and patients with kidney disease, which would agree with the decisive influence of glycemic control in defining epigenetic changes before the occurrence of complications (Fig. 5A and Supplementary
These results were supported by other important tissues in diabetic disease, such as adipose tissue, muscle and pancreatic islets. Genome-wide gene-specific DNA methylation in these tissues revealed that not every tissue is affected by diabetes in the same way. As previously reported, the pancreas in diabetes exhibits pronounced

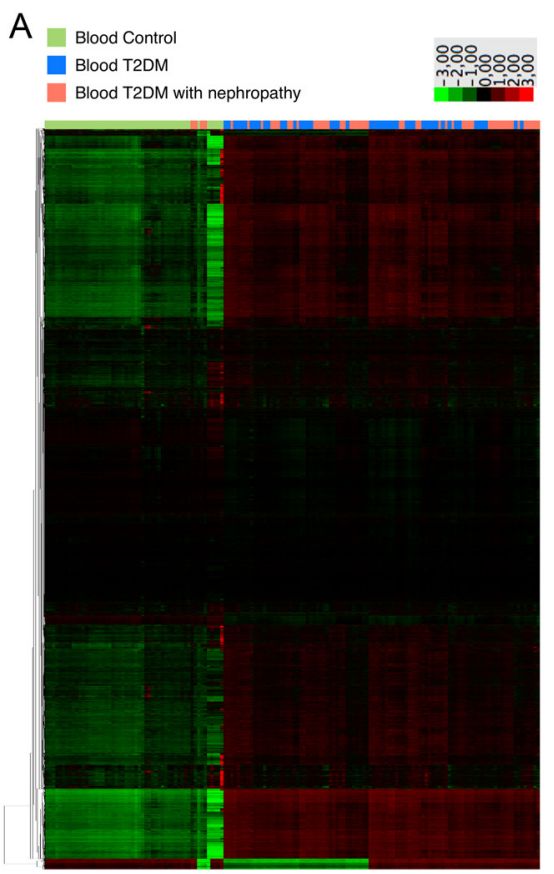

B

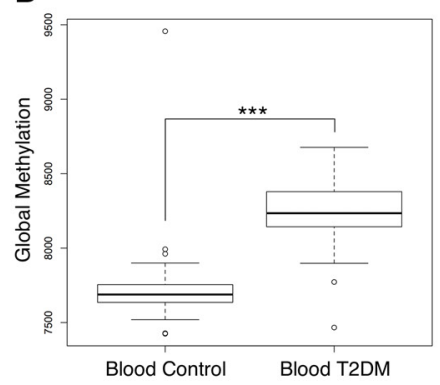

D

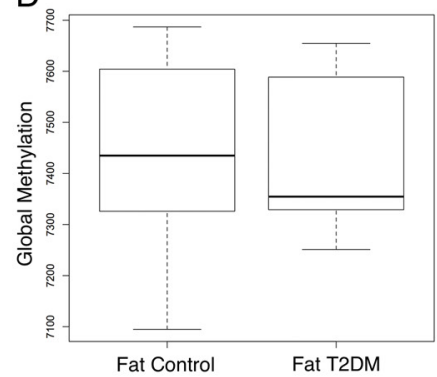

C

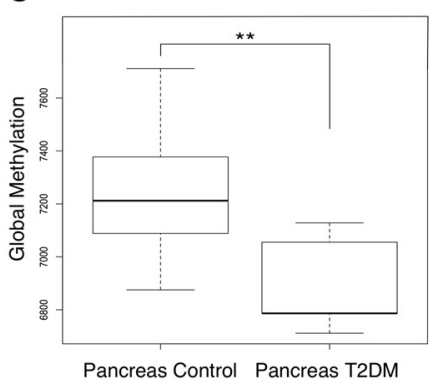

E

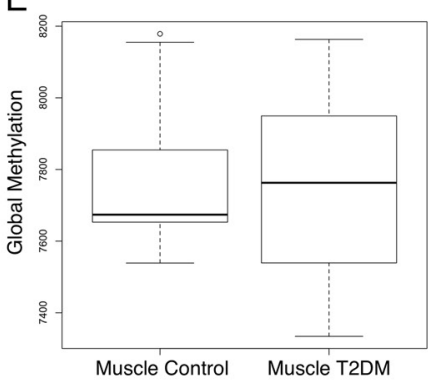

Figure 5

High-throughput methylation comparison among blood of T2DM patients, T2DM patients with nephropathy and controls. (A) Heatmap including the data for 317 Illumina Human Methylation 27 BeadChips (HumanMethylation27_270596_v.1.2) obtained from the experiments: GSE21232 (pancreatic islets), GSE34008 (whole blood), GSE38291 (muscle and adipose tissue), GSE20067 (whole blood), GSE57285 (healthy control) and GSE61611 (healthy control). The heatmap includes all CpG-containing probes with significant methylation changes. In the scale, beta values (that is, the ratio of the methylated probe intensity to the overall intensity, where the overall intensity is the sum of methylated and unmethylated probe intensities) range from -3 (unmethylated, green) to 3 (completely methylated, red). (B, C, D and E) Comparison of the levels of global methylation in the MFI (mean fluorescence intensity units) between patients with T2DM and controls in peripheral blood, pancreas, fat and muscle, respectively. The comparison was conducted using Student's $T$ test, Welch $T$ test or Wilcoxon test according to data normality. ${ }^{*} P<0.05, * * P<0.01$, and $* * * P<0.001$.

http://www.endocrineconnections.org DOI: 10.1530/EC-17-0199 (c) 2017 The authors Published by Bioscientifica Ltd

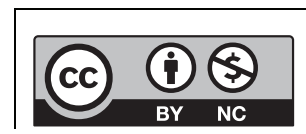

This work is licensed under a Creative Commons Attribution-NonCommercial 4.0 International License. 
A

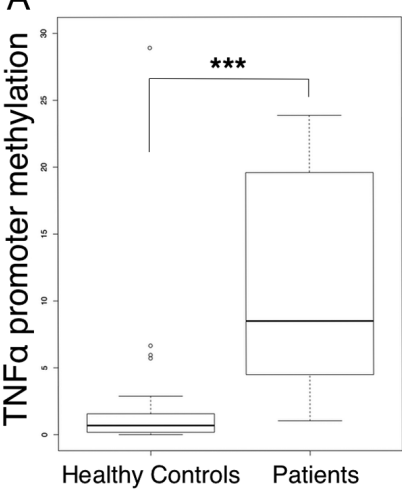

D

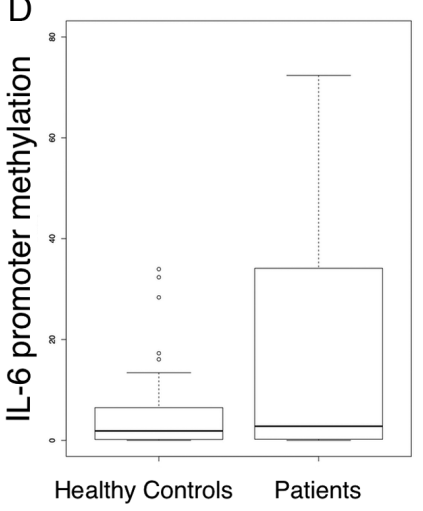

B

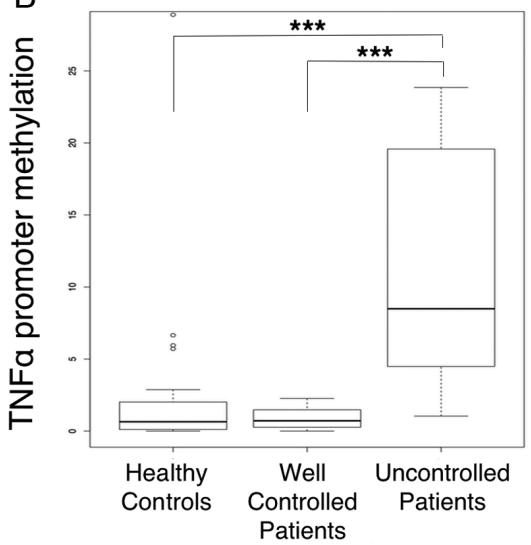

E

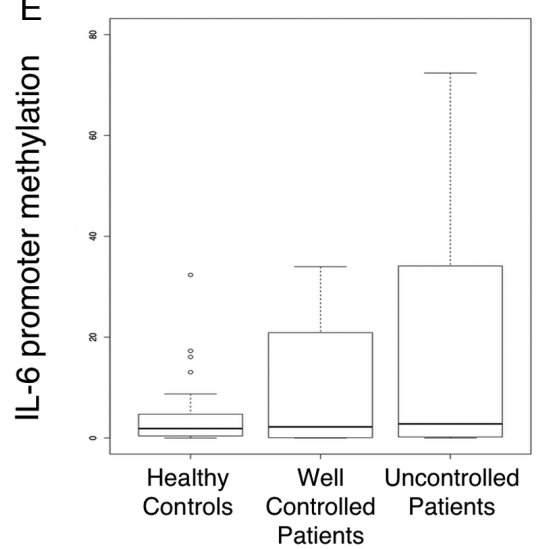

C

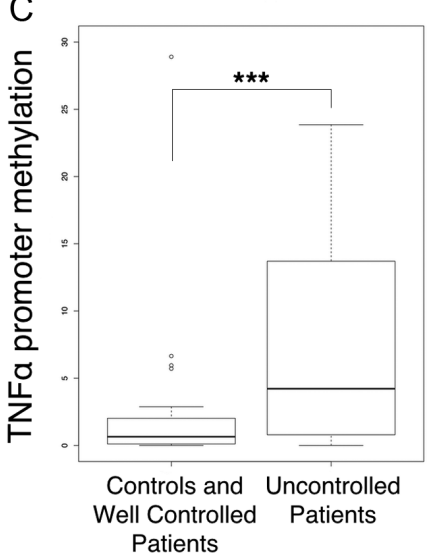

$\mathrm{F}$

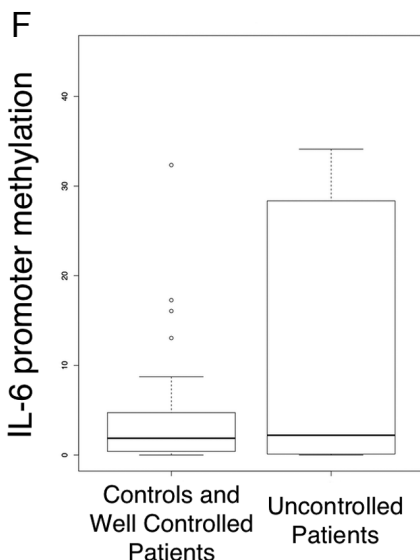

Figure 6

Relative degree of TNF- $\alpha$ and IL- 6 promoter methylation. (A) TNF- $\alpha$ expression in healthy controls vs patients. (B) TNF- $\alpha$ expression in healthy controls, controlled patients and poorly controlled patients. (C) TNF- $\alpha$ expression in healthy controls and controlled patients vs poorly controlled patients. (D) IL- 6 expression in healthy controls vs patients. (E) IL- 6 expression in healthy controls, controlled patients and poorly controlled patients. (F) IL- 6 expression in healthy controls and controlled patients vs poorly controlled patients. Relative promoter methylation was estimated from qMS-PCR. The comparison was conducted using the Wilcoxon rank sum test. $* P<0.05, * * P<0.01$, and $* * * P<0.001$.

hypomethylation $(P=0.007)$, while there were no significant differences between patients and controls in adipose tissue or muscle (Fig. 5C, D and E).

\section{Specific promoter DNA methylation in blood: TNF- $\alpha$ and IL-6}

To compare the results of global DNA methylation with the specific expression of some genes involved in the pathophysiology of diabetes, we performed methylationspecific qPCR to quantify the relative methylation levels of TNF- $\alpha$ and IL- 6 promoters, which represent genes related to inflammation. The promoter of TNF- $\alpha$ was markedly undermethylated in healthy subjects and well-controlled patients compared to uncontrolled patients $(P<0.001)$ (Fig. 6A, B and C). This difference was undoubtedly significant, reflecting the degree of difference encountered in the groups. This is compatible (c) 2017 The authors

http://www.endocrineconnections.org DOI: 10.1530/EC-17-0199 with the previous results of global patterns of DNA $5 \mathrm{mC}$. The relative methylation of the IL- 6 promoter was not significantly different in the analyzed subgroups, nor was it correlated with HbA1c (Fig. 6D, E and F), but high levels of the methylated promoter were also found in uncontrolled patients.

\section{Specific promoter DNA methylation in other tissues: TNF- $\alpha$ and IL- 6}

We analyzed TNF- $\alpha$ and IL- 6 promoter methylation in published data from microarrays in the blood, pancreas, muscle and adipose tissue. Unlike what was found in our sample, there were no differences in the methylation of the TNF- $\alpha$ promoter in blood, which was possibly due to the lack of information regarding glycemic control. No other difference was found in the remaining tissues (Fig. 7A, B, C and D).

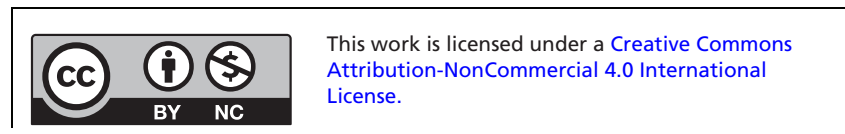


A Blood

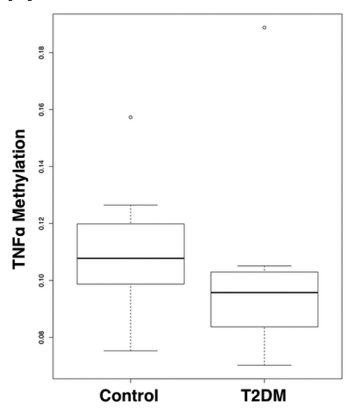

E

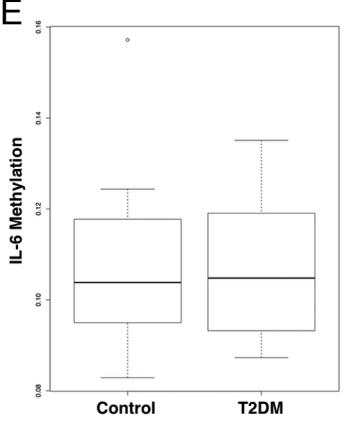

B

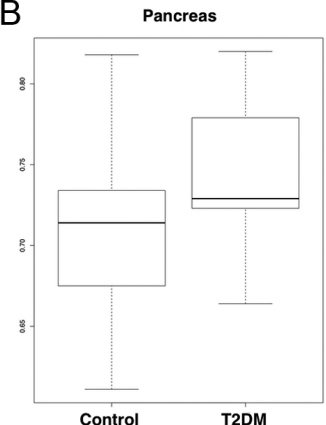

F

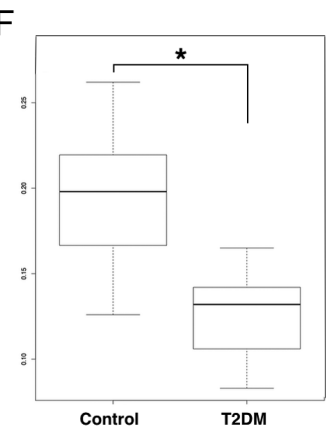

C

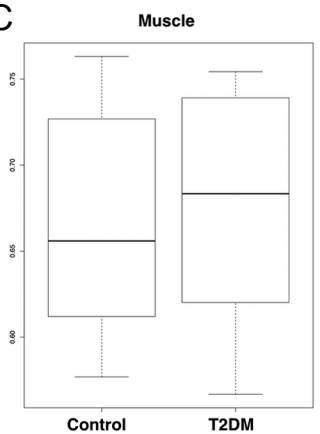

D

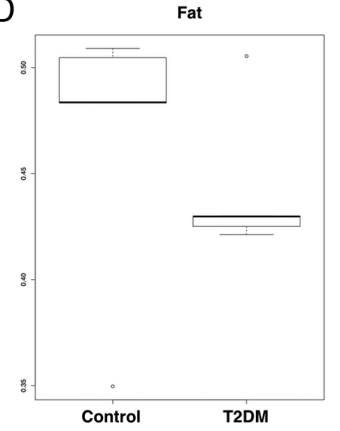

G

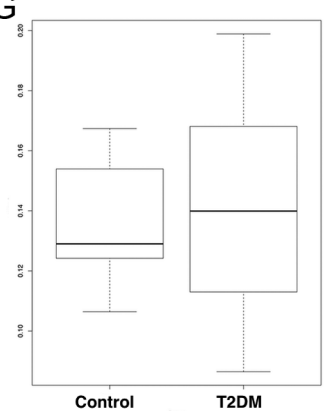

$\mathrm{H}$

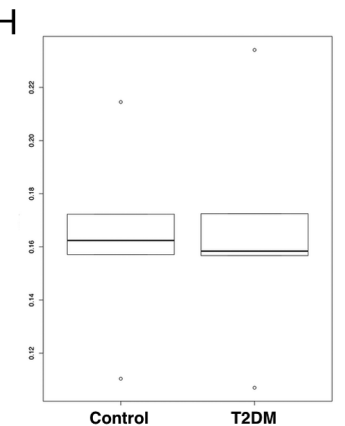

\section{Figure 7}

Promoter methylation of TNF- $\alpha$ and IL- 6 by the microarray analysis in the peripheral blood, pancreas, muscle and fat of healthy controls and patients with T2DM. (A) TNF- $\alpha$ methylation in blood, (B) TNF- $\alpha$ methylation in pancreas, (C) TNF- $\alpha$ methylation in muscle, (D) TNF- $\alpha$ methylation in fat, (E) IL- 6 methylation in blood, (F) IL-6 methylation in pancreas, (G) IL-6 methylation in muscle and (H) IL-6 methylation in fat. The comparison was conducted using the Wilcoxon rank sum test. ${ }^{*} P<0.05, * * P<0.01$, and $* * * P<0.001$. The data for 317 Illumina Human Methylation 27 BeadChips (HumanMethylation27_270596_v.1.2) obtained from the experiments, GSE21232 (pancreatic islets), GSE34008 (whole blood), GSE38291 (muscle and adipose tissue), GSE20067 (whole blood), GSE57285 (healthy control) and GSE61611 (healthy control), were used for this comparison.

Regarding the methylation of IL-6, there were only differences in the pancreas for which a much lower methylation was observed in patients compared to healthy controls $(P=0.0147)$ (Fig. 7F). This low methylation of the promoter perfectly correlates with the substantial increase in the expression found in this tissue in expression microarrays $(P<0.001)$ (Fig. 8B).

However, there was no difference in the blood, which is consistent with the data obtained in our sample (Fig. 7E). Despite the lack of differences at the methylation level of the promoter, we found a lower expression of the gene in the expression microarray $(P<0.001)$ (Fig. 8A). There were also no differences in the fat and muscle (Fig. 7E, F, $\mathrm{G}$ and $\mathrm{H}$ ).

\section{Analysis of the molecular machinery involved in methylation changes in the blood}

The best-described pathway of active DNA demethylation involves several genes and pathways (DNA oxidases and several DNA repair systems). To test whether this process was occurring in our sample and its relationship with blood glucose levels, we measured the expression of several of these genes in leukocytes from the three groups of participants in the study including DNMT1, TET1 AID and OGG1 (8-Oxo guanine binding protein) (Fig. 9 and Supplementary Fig. 3).
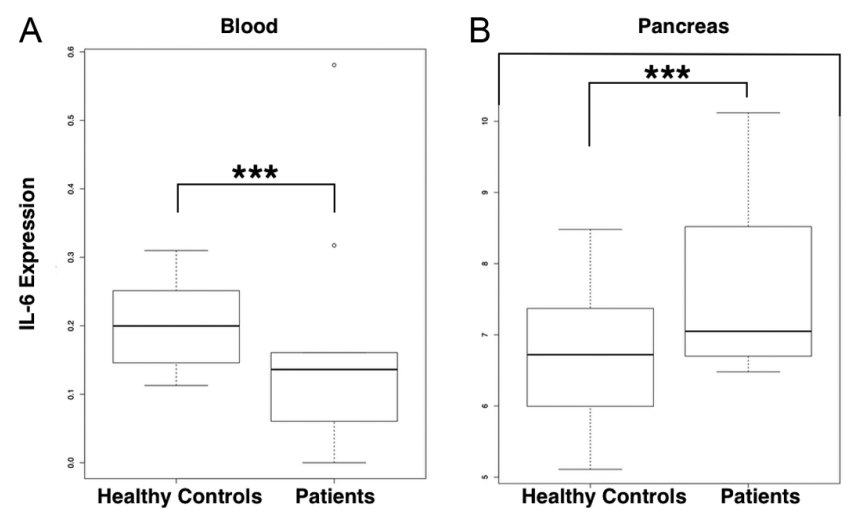

Figure 8

Analysis of IL- 6 expression by the microarray analysis in the peripheral blood (A) and pancreas (B) of healthy controls and patients with T2DM. The comparison was conducted using the Wilcoxon rank sum test. $* P<0.05, * * P<0.01$, and $* * * P<0.001$. Gene expression was studied from GEO datasets GSE26168 and GSE38642.

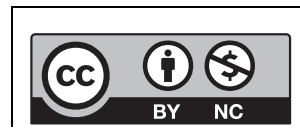

This work is licensed under a Creative Commons Attribution-NonCommercial 4.0 International License. 
A
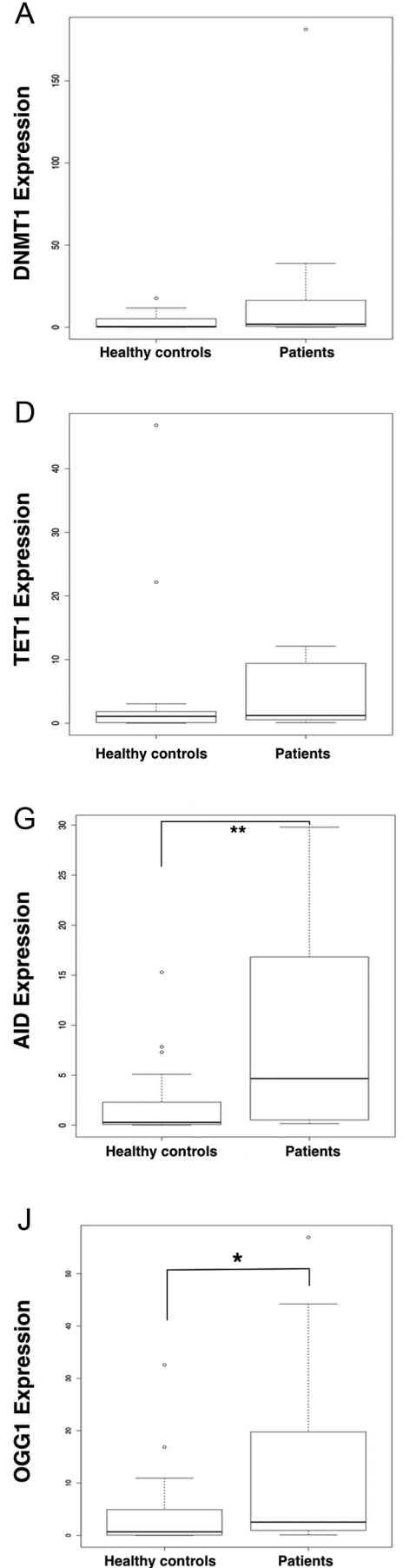

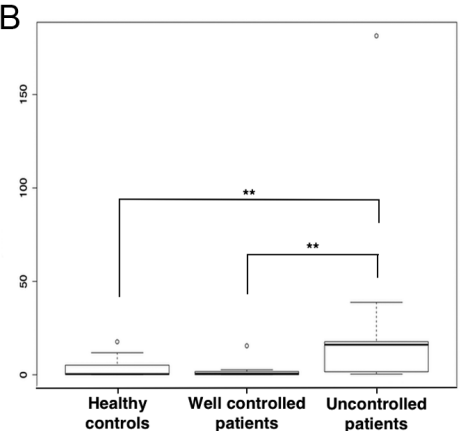

E
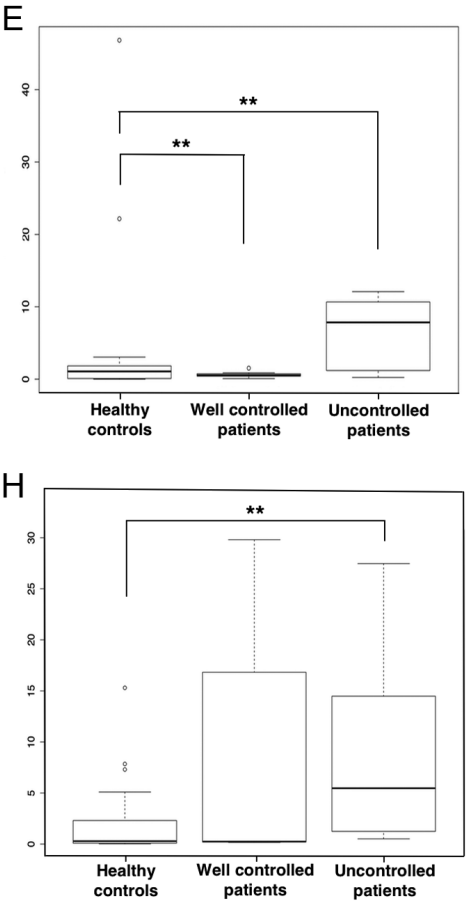

K

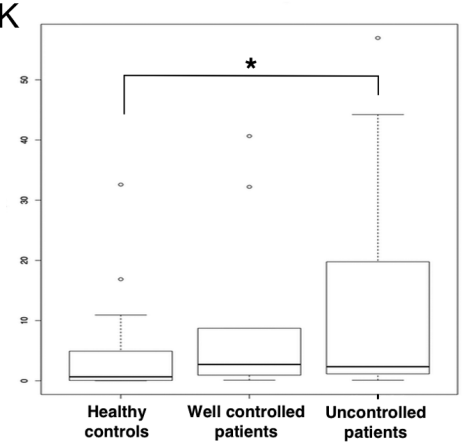

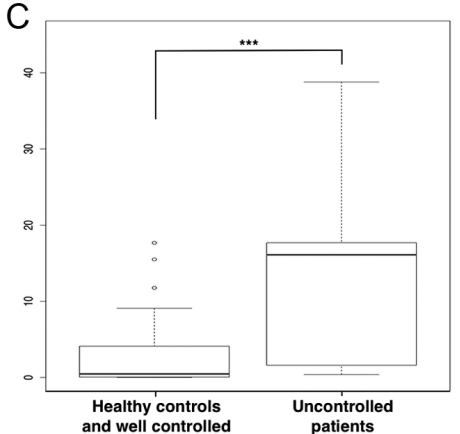

patients

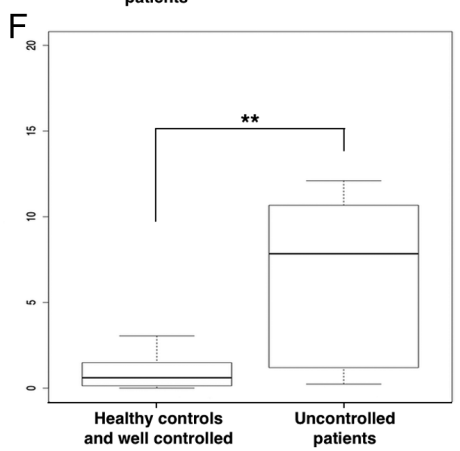

patients

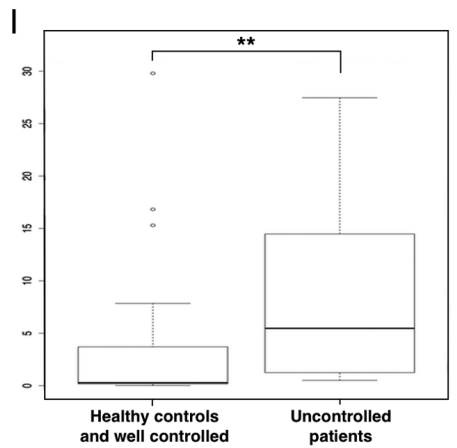

L

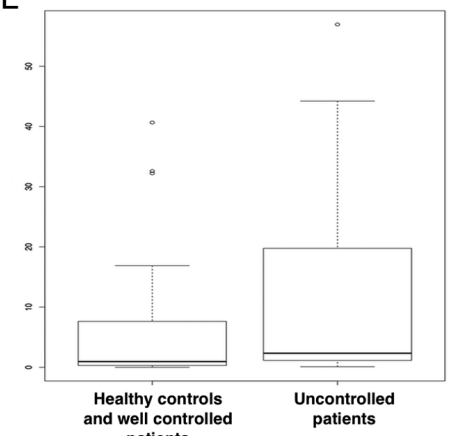

Figure 9

Analysis of DNMT1, TET1, AID and OGG1 expression in the peripheral blood of controls and patients with T2DM. (A) DNMT1 expression in healthy controls vs patients. (B) DNMT1 expression in healthy controls, controlled patients and poorly controlled patients. (C) DNMT1 expression in healthy controls and controlled patients vs poorly controlled patients. (D) TET1 expression in healthy controls vs patients. (E) TET1 expression in healthy controls, controlled patients and poorly controlled patients. (F) TET1 expression in healthy controls and controlled patients vs poorly controlled patients. (G) AID expression in healthy controls vs patients. (H) AID expression in healthy controls, controlled patients and poorly controlled patients. (I) AID expression in healthy controls and controlled patients vs poorly controlled patients and DNMT1 expression in healthy controls vs patients. (J) OGG1 expression in healthy controls vs patients. (K) OGG1 expression in healthy controls, controlled patients and poorly controlled patients. (L) OGG1 expression in healthy controls and controlled patients vs poorly controlled patients. The comparison was conducted using the Wilcoxon rank sum test. * $P<0.05$, $* * P<0.01$, and $* * * P<0.001$. The method used to estimate the gene expression was GRT-PCR, using GAPDH as internal control of gene expression.

http://www.endocrineconnections.org DOI: 10.1530/EC-17-0199 (c) 2017 The authors Published by Bioscientifica Ltd

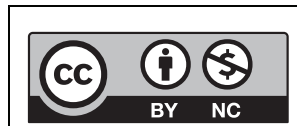

This work is licensed under a Creative Commons Attribution-NonCommercial 4.0 International License. 
A

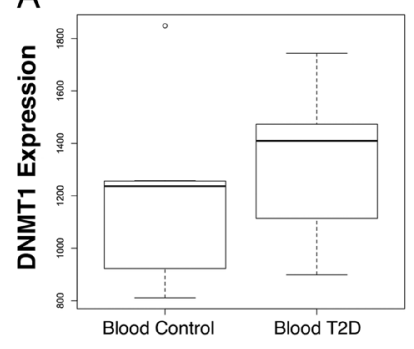

E

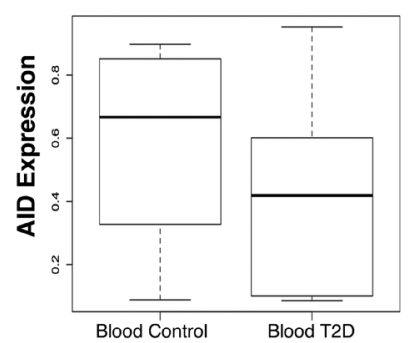

B

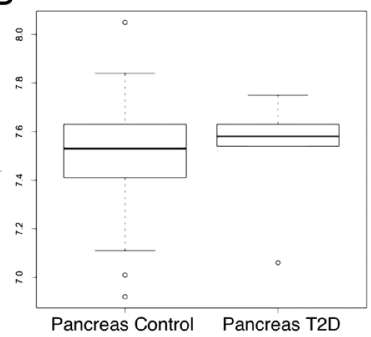

F

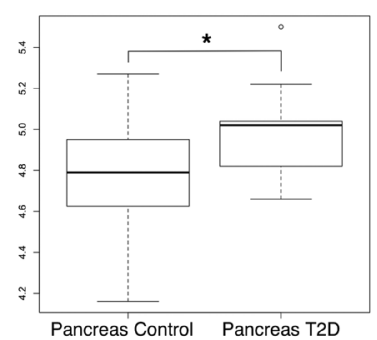

C

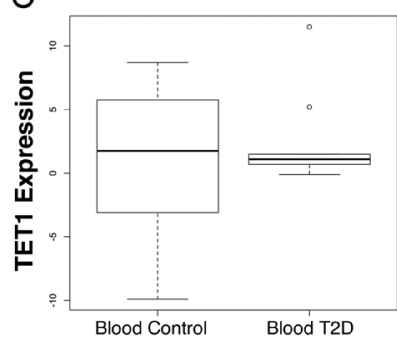

G

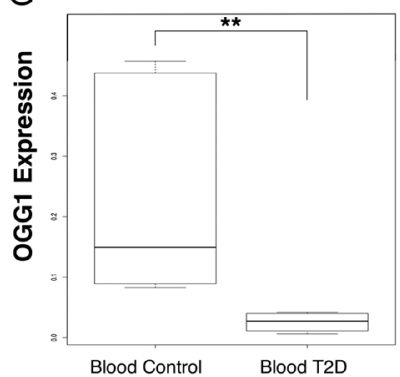

D

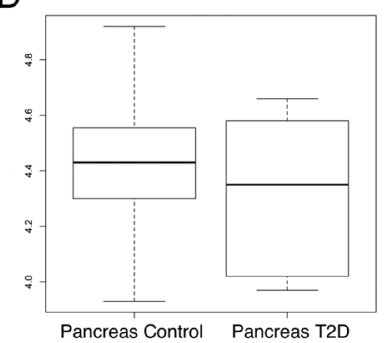

$\mathrm{H}$

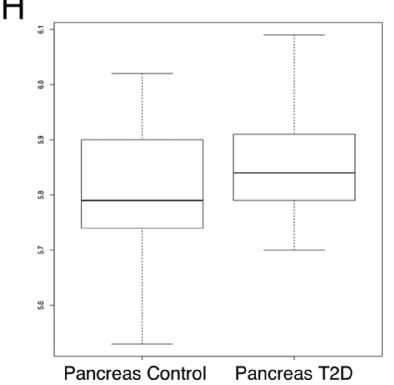

Figure 10

Expression of DNMT1, TET1, AID and OGG1 by the microarray analysis in the peripheral blood and pancreas of controls and patients with T2DM. (A) DNMT1 expression in healthy controls vs patients in blood. (B) DNMT1 expression in healthy controls vs patients in the pancreas. (C) TET1 expression in healthy controls vs patients in blood. (D) TET1 expression in healthy controls vs patients in the pancreas. (E) AID expression in healthy controls vs patients in blood. (F) AID expression in healthy controls vs patients in blood in the pancreas. (G) OGG1 expression in healthy controls vs patients in blood. (H) OGG1 expression in healthy controls vs patients in the pancreas. The comparison was conducted with the Wilcoxon rank sum test. * $P<0.05$, $* * P<0.01$, and $* * * P<0.001$. Gene expression was studied from GEO datasets GSE26168 and GSE38642.

When we analyzed the DNMT1 expression profile, we found that patients with higher HbA1c levels had higher levels of mRNA for this gene (correlation $P=0.0085$ ) (Supplementary Fig. 3C), implying increased activity of its principal described function in the maintenance of DNA methylation patterns (Fig. 9A, B and C). In the studied subgroups, uncontrolled patients had higher levels of DNMT1, and this difference was statistically significant $(P<0.01)$ (Fig. 9B). This difference was greater when joining healthy controls and well-controlled patients compared to uncontrolled patients $(P<0.001)$ (Fig. 9C).

Regarding the expression of DNA-oxygenase TET1 mRNA, its levels increased linearly as the glucose levels of patients were higher in a similar way as the DNMT1 gene expression (correlation Tau $=0.2248, \quad P=0.045$ ) (Supplementary Fig. 3F). In the subgroup analysis, the difference was specifically significant when uncontrolled patients were separated from the rest of the sample $(P=0.003)$ (Fig. 9F). As it is possibly involved in DNA oxidation and demethylation, its expression is consistent with the levels of $5 \mathrm{hmC}$, one of the confirmed products of its enzymatic activity.

We also evaluated the expression of the AID and OGG1 genes. Both were positively correlated with the glycated hemoglobin levels in the samples
(Supplementary Fig. 3I and L). In the groups, AID showed an interesting behavior that differed from the other analyzed proteins; it was increased in uncontrolled patients $(P<0.01)$ (Fig. 9I), but well-controlled patients also had elevated levels of expression without a significant difference in this case (Fig. 9H). The levels of DNA-damage response protein OGG1 were higher in the patient subgroup $(P<0.05)$ (Fig. 9J), but this difference did not increase when we further subdivided the sample $(P<0.05)$ (Fig. 9K). These two DNA repair enzymes have been involved in the mechanism of DNA demethylation, which is downstream of the TET family activity. The overexpression of these enzymes would explain the high level of hydroxymethylation found in uncontrolled patients.

\section{Analysis of the molecular machinery involved in methylation changes in other tissues}

We also analyzed the expression and promoter methylation of these genes (DNMT1, TET1, AID and OGG1) involved in demethylation mechanisms in published microarray data of the blood and pancreas. In addition, other genes such as TET2, TET3, other DNMTs, UHRF1 (ubiquitin-like with PHD and ring finger domains 1) and the APOBECs

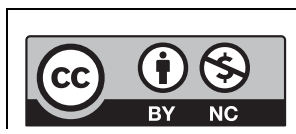

This work is licensed under a Creative Commons Attribution-NonCommercial 4.0 International License. 
(apolipoprotein B mRNA editing enzyme family) were analyzed in different tissues. We also analyzed miR-133a, a negative regulator of DNMT1.

In comparing expression levels from microarrays of blood samples from healthy individuals and patients with diabetes, we found no differences that could directly explain the increase in methylation. Nonetheless, the most important finding was probably the lower expression of AID and OGG1 in patients, and the latter was significant $(P<0.01)$ (Fig. 10E and G).

There were significantly higher levels of DNMT2 expression among controls $(P=0.031$, Supplementary Fig. 4). However, the function of this enzyme, currently associated with RNA methylation, does not seem to explain the change. Analysis of miR-133a did not reveal any significant change. By contrast, there were differences in APOBEC3B and APOBEC3D $(P=0.017$ and $P=0.042$, respectively) (Supplementary Fig. $4 \mathrm{~K}$ and L).

Similar results were observed in pancreatic tissue microarrays. There were no differences in DNMT1 expression levels, which could explain a passive demethylation process, and the differences in TET enzymes were limited to a significant decrease in TET2 in samples of diabetes, which could not explain an active demethylation process $(P=0.031)$ (Supplementary Fig. 5F). However, we observed a higher expression of AID in diabetic pancreatic tissue, an interesting finding in a tissue with a clear global demethylation $(P=0.017)$ according to its role in the final pathway of DNA demethylation (Fig. 10F).

\section{Discussion}

\section{$5 \mathrm{mC}$ and $5 \mathrm{hmC}$ levels are associated with glycemic control in T2DM}

Our study found differences between T2DM patients and controls in global DNA methylation and hydroxymethylation in peripheral blood cells, and there were higher levels among patients in both cases. While our findings contrast with most other studies of epigenetic alterations in T2DM, it should be considered that each tissue reacts differently to cellular stress. Therefore, while hypomethylation in endothelial and pancreatic islets seems to be the dominant characteristic of diabetes, the opposite seems to occur in blood cells $(1,16,17,23,34$, $36,37,38)$. One possible explanation for this finding is the higher rate of replacement of blood cells relative to other tissues. In any case, it is remarkable to observe how the DNA methylation levels seem to be saturated in relation to the degree of diabetes control. There was an increase in methylation in patients that was proportional to the glycosylated hemoglobin levels up to $10 \%$. However, methylation was drastically reduced in the worst controlled of all patients (HbA1c\% > 10\%) (Supplementary Fig. 1G). This gives an idea of how important cellular oxidation seems to be for all epigenetic control, and it may be the cause of many alterations observed globally and in the regulation of the studied genes.

Concerning the effect of tobacco and alcohol consumption, it is difficult to accurately examine their separate effects given the small number of self-reported consumers (10 cigarette smokers and 6 alcohol users) and frequent concurrent use of tobacco and alcohol. Alcohol consumption has been associated with high homocysteine levels, which may indicate low SAM and thus low methylation capacity $(39,40)$. Of note, alcohol affects many intermediaries in folate and one-carbon metabolism cycles. Chronic heavy alcohol has also been associated with hypermethylation at specific HspII and MspI restriction sites, which leads to decreased expressions of DNMT3a and DNMT3b and eventually to generalized hypomethylation (41). Furthermore, exposure to cigarette smoke, both in the prenatal stage and during adult life, has also been associated with a reduction in DNA methylation (42).

One of the most surprising findings in our study was the lack of differences in global DNA methylation and hydroxymethylation between well-controlled patients and healthy controls. This suggests that there is a direct relationship between chronic hyperglycemia and cumulative changes in the epigenome; also, there may be a role for global epigenetic changes in mediating the metabolic memory that strongly influences the development of complications. The observation that controlled patients that do not differ from healthy controls demonstrates that it is not the disease per se that causes epigenetic changes; instead, these changes are associated with the cellular dynamics of glucose handling, possibly through oxidative stress, a commonly defined pathway in generating diabetes complications.

This novel result is confirmed by analyzing all the studied variables and their possible influence on the changes found. Again, the importance of glycosylated hemoglobin levels, and hence cell oxidation, is confirmed, explaining the levels of $5 \mathrm{mC}$ and $5 \mathrm{hmC}$. It is important to emphasize the importance of the time of diagnosis as an explanatory variable of the changes of methylation and hydroxymethylation. In addition, age also appears as an important variable. Since its demethylator effect is well known, the small difference in mean age presented

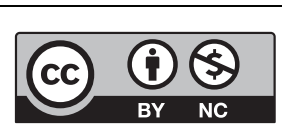

This work is licensed under a Creative Commons Attribution-NonCommercial 4.0 International License. 
by the group of patients may be overshadowing a greater hypermethylating effect of diabetes.

The evaluation of TNF- $\alpha$ and IL- 6 promoter methylation reveals differences in the tissues. Recent studies on T1DM patients have shown that there is no inverse relationship between promoter methylation of TNF- $\alpha$ and mRNA and protein expression, as might be expected (43). These data agree with our results. The lack of differences in TNF- $\alpha$ methylation in the evaluated tissues, regardless of the important role in inflammatory diseases, suggests another mechanism of gene expression regulation independent of DNA promoter methylation. Regarding IL-6, the methylation of its promoter was particularly different in pancreatic islets where there seems to be a correlation between the lack of methylation of the promoter and an increase in the expression of the mRNA (Figs 7F and 8B).

\section{The demethylation pathway}

The study of $5 \mathrm{hmC}$ production as a relevant biological mechanism for DNA demethylation has recently gained considerable attention (29). Although two mechanisms have been clearly described in normal physiology (passive demethylation by lack of maintenance and active demethylation mediated by TET enzymes), the mechanisms by which they are affected in specific diseases and the precise active enzymatic pathways are insufficiently understood.

In this study, we did not find changes in the pancreatic or peripheral blood gene expression of any DNMT that could explain the passive DNA demethylation process, or in the TET enzymes that could explain the active DNA demethylation process.

As for global DNA methylation and hydroxymethylation levels, we only found differences in the gene expression profile when poorly controlled patients were evaluated separately. The expression of DNMT1, TET1, AID and OGG1 in our samples of poorly controlled patients was increased, which can ultimately explain both the increase in DNA methylation by DNMT1 and DNA hydroxymethylation by TET1 (Fig. 9). This result supports the fact that glycemic control is what differentiates patients and their future complications as well as reinforces the need for adequate dietary and pharmacologic control to prevent both the metabolic deterioration associated with this disease and the epigenomic effects that could otherwise result in unbalanced gene expression. Controlling the cellular oxidation generated by inadequate glycemic control allows for closer to normal control of the DNA demethylation machinery and thus the epigenetic outcome.

When we compared our results with the microarray data analysis, there were no differences in the expression profiles of the same genes in the pancreas when comparing samples with T2DM and controls (Fig. 10). The only differentially expressed protein was AID, and its results were the same as those with our sample analysis; it was overexpressed in diabetic patients in the pancreatic tissue (Fig. 10F). This increase in AID can explain how DNA demethylation occurs once the TET enzymes oxidize $5 \mathrm{mC}$ to $5 \mathrm{hmC}$. This result was similar for the OGG1 expression, which has been recently revealed as the last major effector in the process of demethylation (44).

The high expression of TET1, AID and OGG1 in patients, and especially in poorly controlled patients, explains the process of demethylation observed in this disease in most tissues. However, in blood, only the increase in TET1 is consistent with the observed results at the 5 hmC levels.

Beyond these results, it is curious that the expression of these enzymes strongly correlates with increased cellular oxidation, as measured indirectly by the glycated hemoglobin levels (Supplementary Fig. 3), and with the methylation and hydroxymethylation levels (Supplementary Fig. 1). These data suggest that the oxidation is a sine qua non for the start of the demethylation process and that a first oxidation process allows for activation of genes as important as the TET enzymes, which will enhance the oxidation process. In this way, the spontaneous oxidation in blood could facilitate activation of DNMT1, which could eventually lead to the hypermethylation found in this tissue. The same increase in ROS production and redox imbalance leading to epigenetic alterations might be expected under the conditions of chronic inflammation, such as autoimmune diseases or some cancers.

\section{Supplementary data}

This is linked to the online version of the paper at http://dx.doi.org/10.1530/ EC-17-0199.

\section{Declaration of interest}

The authors declare that there is no conflict of interest that could be perceived as prejudicing the impartiality of the research reported.

\section{Funding}

This study was funded by the Vice presidency of Research of The Universidad de los Andes.

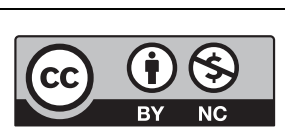

This work is licensed under a Creative Commons Attribution-NonCommercial 4.0 International License. 


\section{Author contribution statement}

J A Pinzón-Cortés: Implementation and data collection, analysis and interpretation of the data, and writing of the paper. A Perna-Chaux: Implementation and data collection, analysis and interpretation of the data. N Rojas: Implementation and data collection and analysis and interpretation of the data. A Díaz-Basabe: Implementation and data collection, analysis and interpretation of the data, database management, and writing of the paper. D C Polania-Villanueva: Critical review of the paper. M F Jacome: Critical review of the paper. C O Mendivil: Writing and critical review of the paper. $\mathrm{H}$ Groot: Critical review of the paper. V LópezSegura: Conception and design of the study, database management, analysis and interpretation of the data, library search and assembly of relevant literature, and writing of the paper.

\section{Acknowledgements}

The authors would like to thank the patients, the Endocrinology Section of the Hospital Universitario Fundación Santa Fe de Bogotá (Colombia) for the samples and clinical support and the Vice Presidency of Research of the Universidad de los Andes (Colombia) for funding this study.

\section{References}

1 Brownlee M. The pathobiology of diabetic complications: a unifying mechanism. Diabetes 200554 1615-1625. (doi:10.2337/ diabetes.54.6.1615)

2 Shaw JE, Sicree RA \& Zimmet PZ. Global estimates of the prevalence of diabetes for 2010 and 2030. Diabetes Research and Clinical Practice 201087 4-14. (doi:10.1016/j.diabres.2009.10.007)

3 Inadera H. Developmental origins of obesity and type 2 diabetes: molecular aspects and role of chemicals. Environmental Health and Preventive Medicine 201318 185-197. (doi:10.1007/s12199-0130328-8)

4 Salbaum JM \& Kappen C. Responses of the embryonic epigenome to maternal diabetes. Birth Defects Research Part A: Clinical and Molecular Teratology 201294 770-781. (doi:10.1002/bdra.23035)

5 Desiderio A, Spinelli R, Ciccarelli M, Nigro C, Miele C, Beguinot F \& Raciti GA. Epigenetics: spotlight on type 2 diabetes and obesity. Journal of Endocrinological Investigation 201639 1095-103. (doi:10.1007/s40618-016-0473-1)

6 Lawlor N, Khetan S, Ucar D \& Stitzel ML. Genomics of islet (Dys) function and Type 2 diabetes. Trends in Genetics 201733 244-255. (doi:10.1016/j.tig.2017.01.010)

7 Ling C, Del Guerra S, Lupi R, Rönn T, Granhall C, Luthman H, Masiello P, Marchetti P, Groop L \& Del Prato S. Epigenetic regulation of PPARGC1A in human type 2 diabetic islets and effect on insulin secretion. Diabetologia 200851 615-622. (doi:10.1007/s00125-0070916-5)

8 Park JH, Stoffers DA, Nicholls RD \& Simmons RA. Development of type 2 diabetes following intrauterine growth retardation in rats is associated with progressive epigenetic silencing of Pdx1. Journal of Clinical Investigation 2008118 2316-2324. (doi:10.1172/JCI33655)

9 Sommese L, Zullo A, Mancini FP, Fabbricini R, Soricelli A \& Napoli C. Clinical relevance of epigenetics in the onset and management of type 2 diabetes mellitus. Epigenetics 201712 401-415. (doi:10.1080/1 5592294.2016.1278097)

10 Fuschi P, Maimone B, Gaetano C \& Martelli F. Noncoding RNAs in the vascular system response to oxidative stress. Antioxidants and Redox Signaling 2017 [in press]. (doi:10.1089/ars.2017.7229)

11 Intine RV \& Sarras MP. Metabolic memory and chronic diabetes complications: potential role for epigenetic mechanisms. Current Diabetes Reports 201212 551-559. (doi:10.1007/s11892-012-0302-7)

12 El-Osta A, Brasacchio D, Yao D, Pocai A, Jones PL, Roeder RG, Cooper ME \& Brownlee M. Transient high glucose causes persistent epigenetic changes and altered gene expression during subsequent normoglycemia. Journal of Experimental Medicine 2008205 2409-2417. (doi:10.1084/jem.20081188)

13 Cooper ME \& El-Osta A. Epigenetics: mechanisms and implications for diabetic complications. Circulation Research 2010107 1403-1413. (doi:10.1161/CIRCRESAHA.110.223552)

14 Rakyan VK, Beyan H, Down TA, Hawa MI, Maslau S, Aden D, Daunay A, Busato F, Mein CA, Manfras B, et al. Identification of type 1 diabetes-associated DNA methylation variable positions that precede disease diagnosis. PLOS Genetics 20117 e1002300. (doi:10.1371/journal.pgen.1002300)

15 Volkmar M, Dedeurwaerder S, Cunha DA, Ndlovu MN, Defrance M, Deplus R, Calonne E, Volkmar U, Igoillo-Esteve M, Naamane N, et al. DNA methylation profiling identifies epigenetic dysregulation in pancreatic islets from type 2 diabetic patients. EMBO Journal 201231 1405-1426. (doi:10.1038/emboj.2011.503)

16 Williams KT, Garrow TA \& Schalinske KL. Type I diabetes leads to tissue-specific DNA hypomethylation in male rats. Journal of Nutrition 2008138 2064-2069. (doi:10.3945/jn.108.094144)

17 Williams KT \& Schalinske KL. Tissue-specific alterations of methyl group metabolism with DNA hypermethylation in the Zucker (type 2) diabetic fatty rat. Diabetes/Metabolism Research and Reviews $2012 \mathbf{2 8}$ 123-131. (doi:10.1002/dmrr.1281)

18 Caudill MA, Wang JC, Melnyk S \& Pogribny IP. Intracellular S-adenosylhomocysteine concentrations predict global DNA hypomethylation in tissues of methyl-deficient cystathionine $\beta$-synthase heterozygous mice. Journal of Nutrition 2001131 2811-2818.

19 Chen NC, Yang F, Capecci LM, Gu Z, Schafer AI, Durante W, Yang X-F \& Wang H. Regulation of homocysteine metabolism and methylation in human and mouse tissues. FASEB Journal $2010 \mathbf{2 4}$ 2804-2817. (doi:10.1096/fj.09-143651)

20 Patti M-E \& Corvera S. The role of mitochondria in the pathogenesis of type 2 diabetes. Endocrine Reviews 201031 364-395. (doi:10.1210/ er.2009-0027)

21 Ulrey CL, Liu L, Andrews LG \& Tollefsbol TO. The impact of metabolism on DNA methylation. Human Molecular Genetics 200514 R139-R147. (doi:10.1093/hmg/ddi100)

22 Wallace DC \& Fan W. Energetics, epigenetics, mitochondrial genetics. Mitochondrion 201010 12-31. (doi:10.1016/j.mito.2009.09.006)

23 Chavali V, Tyagi SC \& Mishra PK. MicroRNA-133a regulates DNA methylation in diabetic cardiomyocytes. Biochemical and Biophysical Research Communications 2012425 668-672. (doi:10.1016/j. bbrc.2012.07.105)

24 Tahiliani M, Koh KP, Shen Y, Pastor WA, Bandukwala H, Brudno Y, Agarwal S, Iyer LM, Liu DR, Aravind L, et al. Conversion of 5-methylcytosine to 5-hydroxymethylcytosine in mammalian DNA by MLL partner TET1. Science 2009324 930-935. (doi:10.1126/ science.1170116)

25 Koh KP, Yabuuchi A, Rao S, Huang Y, Cunniff K, Nardone J, Laiho A, Tahiliani M, Sommer CA, Mostoslavsky G, et al. Tet1 and Tet2 regulate 5-hydroxymethylcytosine production and cell lineage specification in mouse embryonic stem cells. Cell Stem Cell 20118 200-213. (doi:10.1016/j.stem.2011.01.008)

26 Klug M, Schmidhofer S, Gebhard C, Andreesen R \& Rehli M. 5-Hydroxymethylcytosine is an essential intermediate of active DNA demethylation processes in primary human monocytes. Genome Biology 201314 R46. (doi:10.1186/gb-2013-14-5-r46)

27 la Rica de L, Rodríguez-Ubreva J, García M, Islam AB, Urquiza JM, Hernando H, Christensen J, Helin K, Gómez-Vaquero C \& Ballestar E. PU.1 target genes undergo Tet2-coupled demethylation and DNMT3b-mediated methylation in monocyte-to-osteoclast differentiation. Genome Biology 201314 R99. (doi:10.1186/gb-201314-9-r99)

28 Valinluck V \& Sowers LC. Endogenous cytosine damage products alter the site selectivity of human DNA maintenance

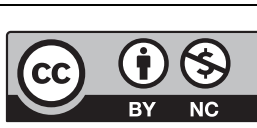


methyltransferase DNMT1. Cancer Research 2007 67 946-950. (doi:10.1158/0008-5472.CAN-06-3123)

29 Branco MR, Ficz G \& Reik W. Uncovering the role of 5-hydroxymethylcytosine in the epigenome. Nature Reviews Genetics 201213 7-13. (doi:10.1038/nrg3080)

30 Pabinger S, Rödiger S, Kriegner A, Vierlinger K \& Weinhäusel A. A survey of tools for the analysis of quantitative PCR (qPCR) data. Biomolecular Detection and Quantification $2014123-33$. (doi:10.1016/j.bdq.2014.08.002)

31 Edgar R, Domrachev M \& Lash AE. Gene expression omnibus: NCBI gene expression and hybridization array data repository. Nucleic Acids Research 200230 207-210. (doi:10.1093/nar/30.1.207)

32 Burchett WW, Ellis AR, Harrar SW \& Bathke AC. Nonparametric inference for multivariate data: the RPackage npmv. Journal of Statistical Software 201776 1-18. (doi:10.18637/jss.v076.i04)

33 Burnham KP, Anderson DR \& Huyvaert KP. AIC model selection and multimodel inference in behavioral ecology: some background, observations, and comparisons. Behavioral Ecology and Sociobiology 201065 23-35. (doi:10.1007/s00265-010-1029-6)

34 Heyn H, Moran S \& Esteller M. Aberrant DNA methylation profiles in the premature aging disorders Hutchinson-Gilford Progeria and Werner syndrome. Epigenetics 20138 28-33. (doi:10.4161/epi.23366)

35 Choi S-W \& Friso S. Nutrients and Epigenetics. Boca Raton, FL, USA: CRC Press, 2009.

36 Olsen AS, Sarras MP \& Intine RV. Limb regeneration is impaired in an adult zebrafish model of diabetes mellitus. Wound Repair and Regeneration 201018 532-542. (doi:10.1111/j.1524-475X.2010.00613.x)

37 Chia N, Wang L, Lu X, Senut M-C, Brenner C \& Ruden DM. Hypothesis: environmental regulation of 5-hydroxymethylcytosine by oxidative stress. Epigenetics 20116 853-856. (doi:10.4161/ epi.6.7.16461)

38 Olsen AS, Sarras MP, Leontovich A \& Intine RV. Heritable transmission of diabetic metabolic memory in zebrafish correlates with DNA hypomethylation and aberrant gene expression. Diabetes 201261 485-491. (doi:10.2337/db11-0588)

39 Bottiglieri T, Laundy M, Crellin R, Toone BK, Carney MW \& Reynolds EH. Homocysteine, folate, methylation, and monoamine metabolism in depression. Journal of Neurology, Neurosurgery, and Psychiatry 200069 228-232. (doi:10.1136/jnnp.69.2.228)

40 Nieratschker V, Batra A \& Fallgatter AJ. Genetics and epigenetics of alcohol dependence. Journal of Molecular Psychiatry 201311. (doi:10.1186/2049-9256-1-11)

41 Bönsch D, Lenz B, Fiszer R, Frieling H, Kornhuber J \& Bleich S. Lowered DNA methyltransferase (DNMT-3b) mRNA expression is associated with genomic DNA hypermethylation in patients with chronic alcoholism. Journal of Neural Transmission 2006113 1299-1304. (doi:10.1007/s00702-005-0413-2)

42 Lee KWK \& Pausova Z. Cigarette smoking and DNA methylation. Frontiers in Genetics 20134 132. (doi:10.3389/fgene.2013.00132)

43 Arroyo-Jousse V, Garcia-Diaz DF, Codner E \& Pérez-Bravo F. Epigenetics in type 1 diabetes: TNFa gene promoter methylation status in Chilean patients with type 1 diabetes mellitus. British Journal of Nutrition 2016116 1861-1868. (doi:10.1017/ S0007114516003846)

44. Zhou X, Zhuang Z, Wang W, He L, Wu H, Cao Y, Pan F, Zhao J, Hu Z, Sekhar C, et al. OGG1 is essential in oxidative stress induced DNA demethylation. Cell Signaling 201628 1163-1171. (doi:10.1016/j. cellsig.2016.05.021)

Received in final form 21 September 2017

Accepted 28 September 2017 http://www.endocrineconnections.org DOI: 10.1530/EC-17-0199
() 2017 The authors Published by Bioscientifica Ltd

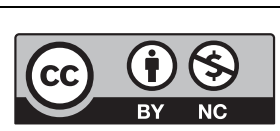

This work is licensed under a Creative Commons Attribution-NonCommercial 4.0 International License. 